\title{
Loop-Mediated Isothermal Amplification for Salmonella Detection in Food and Feed: Current Applications and Future Directions
}

\author{
Qianru Yang, Kelly J. Domesle, and Beilei Ge
}

\begin{abstract}
Loop-mediated isothermal amplification (LAMP) has become a powerful alternative to polymerase chain reaction (PCR) for pathogen detection in clinical specimens and food matrices. Nontyphoidal Salmonella is a zoonotic pathogen of significant food and feed safety concern worldwide. The first study employing LAMP for the rapid detection of Salmonella was reported in 2005, 5 years after the invention of the LAMP technology in Japan. This review provides an overview of international efforts in the past decade on the development and application of Salmonella LAMP assays in a wide array of food and feed matrices. Recent progress in assay design, platform development, commercial application, and method validation is reviewed. Future perspectives toward more practical and wider applications of Salmonella LAMP assays in food and feed testing are discussed.
\end{abstract}

Keywords: LAMP, Salmonella, detection, food, feed

\section{Introduction}

$\mathbf{N}$ ONTYPHOIDAL SALMONELLA is a Gram-negative zoonotic pathogen of substantial public health concern (WHO, 2017). In the 2015 World Health Organization (WHO) estimates of the global burden of foodborne diseases, Salmonella ranked first among 22 bacterial, protozoal, and viral agents, reflecting its ubiquitous nature and the severity of illnesses (Kirk et al., 2015).

In the United States, over $75 \%$ of Salmonella outbreakassociated illnesses were broadly attributed across multiple food categories, including produce, eggs, chicken, pork, and beef (IFSAC 2015, 2017). Salmonella is also recognized as a major microbial hazard in animal food, which includes pet food, animal feed, and raw materials and ingredients (EFSA, 2008; FAO/WHO, 2015; FDA, 2017b). Multistate outbreaks of human salmonellosis linked to tainted pet food have been reported (CDC, 2018). Moreover, some Salmonella serovars are also major animal pathogens, for example, Salmonella Dublin in cattle and Salmonella Gallinarum in poultry, resulting in considerable loss in livestock production (Uzzau et al., 2000; FDA, 2013).

To prevent or reduce Salmonella outbreaks/illnesses from contaminated human or animal food, vigilant product testing and environmental monitoring for pathogens are critical, as underscored by the Food Safety Modernization Act (FSMA) regulations on preventive controls (FDA, 2017a, b). This highlights the importance and urgency to develop rapid, reliable, and robust methods for Salmonella detection in a variety of food and feed matrices.

According to a recent report, the global food microbiology testing for pathogens totaled 280 million tests in 2016, a market valued at $\$ 1.8$ billion (Ferguson, 2017). This represents an increase of $23.2 \%$ in testing volume over a 3-year period. Not surprisingly, Salmonella was the target in $43 \%$ of all tests performed, followed by Listeria and Listeria monocytogenes (41\%), pathogenic Escherichia coli (14\%), and Campylobacter (2\%). A clear shift from traditional methods to rapid methods (e.g., polymerase chain reaction [PCR]) has been the trend observed for all four priority pathogens in the past two decades (Ferguson, 2017).

Loop-mediated isothermal amplification (LAMP) (Notomi et al., 2000) is a novel nucleic acid amplification test (NAAT) that has recently emerged as a powerful alternative to PCR for the rapid detection of various bacterial, fungal, parasitic, and viral agents (Niessen et al., 2013; Li et al., 2017). The first LAMP assay targeting Salmonella was reported in 2005 (Hara-Kudo et al., 2005). Since then, dozens of new

Division of Animal and Food Microbiology, Office of Research, Center for Veterinary Medicine, U.S. Food and Drug Administration, Laurel, Maryland.

(c) Qianru Yang et al., 2018; Published by Mary Ann Liebert, Inc. This Open Access article is distributed under the terms of the Creative Commons License (http://creativecommons.org/licenses/by/4.0), which permits unrestricted use, distribution, and reproduction in any medium, provided the original work is properly cited. 
Salmonella LAMP assays have been developed, leading to broad applications in human food and more recently in animal feed.

This review aims to capture international efforts in the past decade on the development and application of Salmonella LAMP assays in food and feed matrices. Future perspectives toward even more practical and wider applications of such assays in food and feed testing are discussed.

\section{LAMP in a Nutshell}

LAMP was invented in 2000 by a group of Japanese scientists (Notomi et al., 2000). The mechanism is based on the production of a stem-loop DNA structure during initiation steps, which serves as the starting material for second-stage LAMP cycling (refer to this site (Eiken Chemical Co. Ltd., 2005) for LAMP diagrams and animation). Unlike PCR (Table 1) that relies on thermal cycling to denature DNA and enable amplification by Taq DNA polymerase, LAMP uses a strand-displacing Bst DNA polymerase, which allows autocycling amplification under a constant temperature (60$65^{\circ} \mathrm{C}$ ). This obviates the need for a sophisticated thermocycler. There are four to six specially designed LAMP primers (Nagamine et al., 2002), which target six to eight regions of the template DNA, compared to two primers in PCR (plus one or more probes in real-time PCR where amplification and detection occur simultaneously), ensuring a highly specific assay.

LAMP amplifies the target DNA rather efficiently, with $10^{9}$ copies generated within an hour (Notomi et al., 2000). PCR or real-time PCR generally takes $1-2 \mathrm{~h}$ (although speedier versions are available now) and the amount of DNA produced is almost 20 times less (Mashooq et al., 2016). LAMP is highly tolerant to biological substances (Kaneko et al., 2007) with robustness demonstrated in both clinical and food applications (Francois et al., 2011; Yang et al., 2014). PCR, on the other hand, is generally susceptible to various assay inhibitors present in complex food or feed matrices (Abu Al-Soud and Radstrom, 2000; Maciorowski et al., 2005). LAMP is also more versatile in terms of amplicon detection methods, which include naked eye, colorimetry, turbidity, fluorescence, and bioluminescence, among many others (Zhang et al., 2014).

These attractive features of LAMP appear to align well with the WHO-outlined ASSURED (which stands for af- fordable, sensitive, specific, user friendly, rapid and robust, equipment free, and delivered to those who need it) criteria for an ideal diagnostic test (Mabey et al., 2004). As such, LAMP has become a mainstream isothermal NAAT used for low-cost point-of-care (POC) diagnostics and has reached a high level of maturity (Niemz et al., 2011; de Paz et al., 2014). In August 2016, WHO issued a recommendation for a TB-LAMP (LAMP for detection of Mycobacterium tuberculosis) method as a rapid, accurate, and robust replacement test for smear microscopy to diagnose tuberculosis in peripheral health centers (WHO, 2016).

Applications of LAMP also extend to many other fields beyond in vitro diagnostics, as summarized in several recent reviews, such as species authentication and microbiological quality/safety assessment in meats (Kumar et al., 2017), and testing for genetically modified organisms (GMOs), allergens, pesticides, and drug resistance (Kundapur and Nema, 2016). A quick PubMed search using the term "loop-mediated isothermal amplification" returned > 2100 articles, highlighting the great interest in LAMP within the scientific community.

The popularity of LAMP is also reflected in the development of many commercially available systems (Fig. 1). Along with these exciting developments, the LAMP technology has been explored by researchers around the globe for the rapid, reliable, and robust detection of Salmonella in human food and animal food, which is the focus of this review.

\section{Salmonella LAMP Assay Development}

Japanese scientists Hara-Kudo et al. (2005; Ohtsuka et al., 2005) have pioneered the field of LAMP detection for Salmonella in terms of initial assay development and food applications. In 2005, they described the first Salmonella LAMP assay and its application in artificially inoculated as well as naturally contaminated liquid eggs (Hara-Kudo et al., 2005; Ohtsuka et al., 2005). Since 2008, dozens of new Salmonella LAMP assays (i.e., with newly designed primers) have been developed, many of which were summarized in two excellent reviews published in 2013 (Niessen et al., 2013; Kokkinos et al., 2014).

Table 2 presents our collection (through regular PubMed and Web of Science searches and active literature gathering for ongoing research) of all Salmonella LAMP studies $(n=100)$ reported to date, some focusing on new assay developments ( $46 \%$ of studies) or new platform developments

Table 1. Technical Comparison Between Loop-Mediated Isothermal Amplification and Polymerase Chain Reaction (or Real-Time Polymerase Chain Reaction)

\begin{tabular}{|c|c|c|c|}
\hline Assay step & Component & $L A M P$ & $P C R$ or real-time $P C R$ \\
\hline \multirow[t]{3}{*}{ Amplification } & Enzyme & $\begin{array}{l}\text { Bst DNA polymerase or equivalent ones } \\
\text { High strand displacement activity } \\
\text { Autocycling DNA amplification } \\
\text { Isothermal }\left(60-65^{\circ} \mathrm{C}\right)\end{array}$ & $\begin{array}{l}\text { Taq DNA polymerase or equivalent ones } \\
\text { Thermal cycling requirement } \\
\left(95^{\circ} \mathrm{C} / 55^{\circ} \mathrm{C} / 72^{\circ} \mathrm{C}\right)\end{array}$ \\
\hline & Primer & $\begin{array}{l}\text { Four to six, two are longer ones } \\
\text { (double length, } \sim 40 \mathrm{bp} \text { ) }\end{array}$ & $\begin{array}{l}\text { Two, plus one or more probes } \\
\text { (real-time PCR) }\end{array}$ \\
\hline & $\begin{array}{l}\text { Other } \\
\text { reagents }\end{array}$ & dNTP, buffer, $\mathrm{Mg}^{2+}$, water & dNTP, buffer, $\mathrm{Mg}^{2+}$, water \\
\hline Detection & Platform & $\begin{array}{l}\text { Gel electrophoresis, turbidity, naked eye, } \\
\text { colorimetric, fluorescence, bioluminescence, etc. }\end{array}$ & $\begin{array}{l}\text { Gel electrophoresis, fluorescence } \\
\text { (real-time PCR) }\end{array}$ \\
\hline
\end{tabular}

LAMP, loop-mediated isothermal amplification; PCR, polymerase chain reaction. 

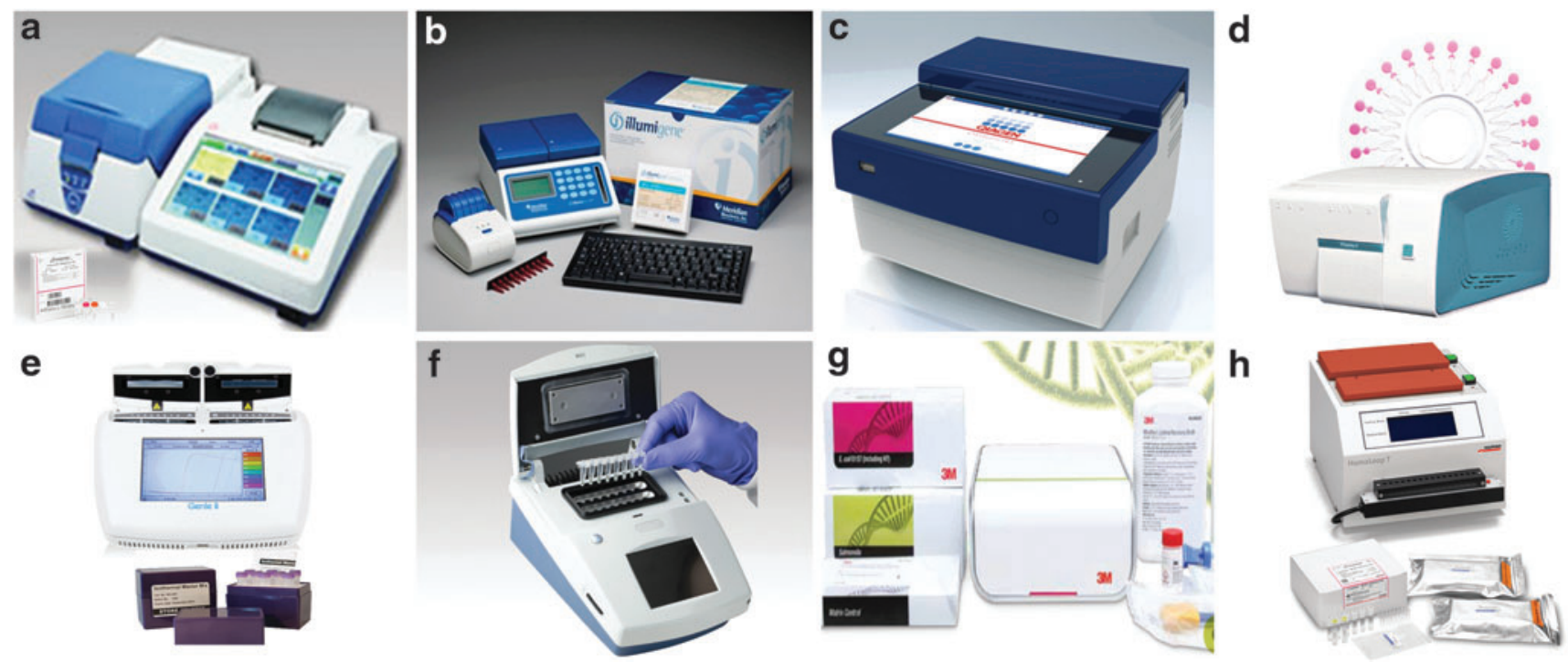

FIG. 1. LAMP commercial applications. (a) Loopamp Realtime Turbidimeter LA-500 and reagent kits (Eiken Chemical Co., Ltd., Tokyo, Japan); (b) illumipro-10 and illumigene Molecular Diagnostic System (Meridian Bioscience, Inc., Cincinnati, OH); (c) ESEQuant TS2 (Qiagen, Venlo, Netherlands); (d) RTisochip-A (CapitalBio Technology Co., Ltd., Beijing, China); (e) Genie II and reagents (OptiGene Ltd., West Sussex, United Kingdom); (f) PDQ (ERBA Molecular, Cambridgeshire, United Kingdom); (g) 3M Molecular Detection System and assays (3M Food Safety, St. Paul, MN); (h) HumaLoop T and assays (HUMAN Diagnostics, Wiesbaden, Germany). LAMP, loop-mediated isothermal amplification.

(34\%), and others on applications in food (63\%) or feed matrices (6\%). Notably, scientists in China (32\% of studies), United States (29\%), Korea (8\%), and Japan (5\%) have contributed most to the advancements in this field.

\section{Primer design}

LAMP primers are commonly designed using the free web-based PrimerExplorer V4 software (V5 is available as of October 2016; http://primerexplorer.jp/e; Fujitsu Ltd., Tokyo, Japan). The LAMP Designer software (PREMIER Biosoft International, Palo Alto, CA) has been developed to serve a similar purpose. Each LAMP primer set contains four primers, two inner primers (FIP, forward inner primer; BIP, backward inner primer) and two outer primers (F3; B3). The inner primers FIP/BIP consist of complementary sequences of F1c/B1c and F2/B2 regions (Eiken Chemical Co. Ltd., 2009).

In earlier Salmonella LAMP studies, a TTTT linker was often added to connect F1c and F2 or B1c and B2 (Wang et al., 2008a; Lu et al., 2009; Zhang et al., 2012). It is now common practice for Salmonella LAMP assays to incorporate two loop primers ( $\mathrm{LF}$, loop forward; LB, loop backward) to accelerate the reaction (Nagamine et al., 2002). Figure 2 illustrates the positions of these primers (or components of FIP/BIP) on the target gene, invA, which we used for a Salmonella LAMP assay (Yang et al., 2016).

The invA gene is the most frequently targeted gene for designing LAMP primers for Salmonella spp. (74\% of articles in Table 2). This gene is 2176 bp long in Salmonella Typhimurium (GenBank accession No. M90846) (Galan et al., 1992). A closer examination of the regions ( $5^{\prime}$ end of $\mathrm{F} 3$ and $3^{\prime}$ end of B3) covered by the primers designed by HaraKudo et al. (2005) and us (Yang et al., 2016) showed that they are in tandem with each other (225-468 and 484-682 bp), both overlapping with the region (371-655 bp) targeted by a set of widely used Salmonella invA PCR primers (Rahn et al., 1992). Sequence analysis showed that other sets of invAbased LAMP primers also overlapped with this PCR region (Chen et al., 2011), while still others targeted downstream regions (Wang et al., 2008b; Shao et al., 2011).

Other target genes, including $b c f D$ and fim $Y$, have also been used to design Salmonella LAMP primers (Table 2). Salmonella LAMP detection kits with proprietary primer information are available commercially, including Loopamp Salmonella Detection Kit (Eiken Chemical Co., Ltd., Tokyo, Japan), 3M Molecular Detection Assay (MDA) 2-Salmonella (3M Food Safety, St. Paul, MN), SAS Molecular Tests Salmonella Detection Kit (SA Scientific Ltd., San Antonio, TX), and Ampli-LAMP Salmonella species (NovaZym, Poznań, Poland).

A few LAMP assays have been developed that target specific Salmonella serovars or serogroups (Table 2). For instance, sdfI (Yang et al., 2010) and prot6E (Hu et al., 2018) were used to design two separate LAMP assays for Salmonella enterica serovar Enteritidis, while typh was used to specifically detect Salmonella Typhimurium (Kumar et al., 2014). The sefA gene has been explored to design a LAMP assay for both Salmonella Enteritidis and Salmonella Gallinarum (Gong et al., 2016). An insertion element IS200/ IS1351 gene was used to detect Salmonella O9 serogroup (Okamura et al., 2008), prt ( $r f b S$ ) for serogroup D (i.e., O9) (Ravan and Yazdanparast 2012a, b), and $r f b J$ for $\mathrm{O} 4$ serogroup (Okamura et al., 2009).

\section{Platform development}

LAMP amplicons can be detected through multiple platforms/methods, as reviewed by Zhang et al. (2014), including naked eye, gel electrophoresis, colorimetry, turbidity, fluorescence, bioluminescence, electrochemical sensors/chips, 


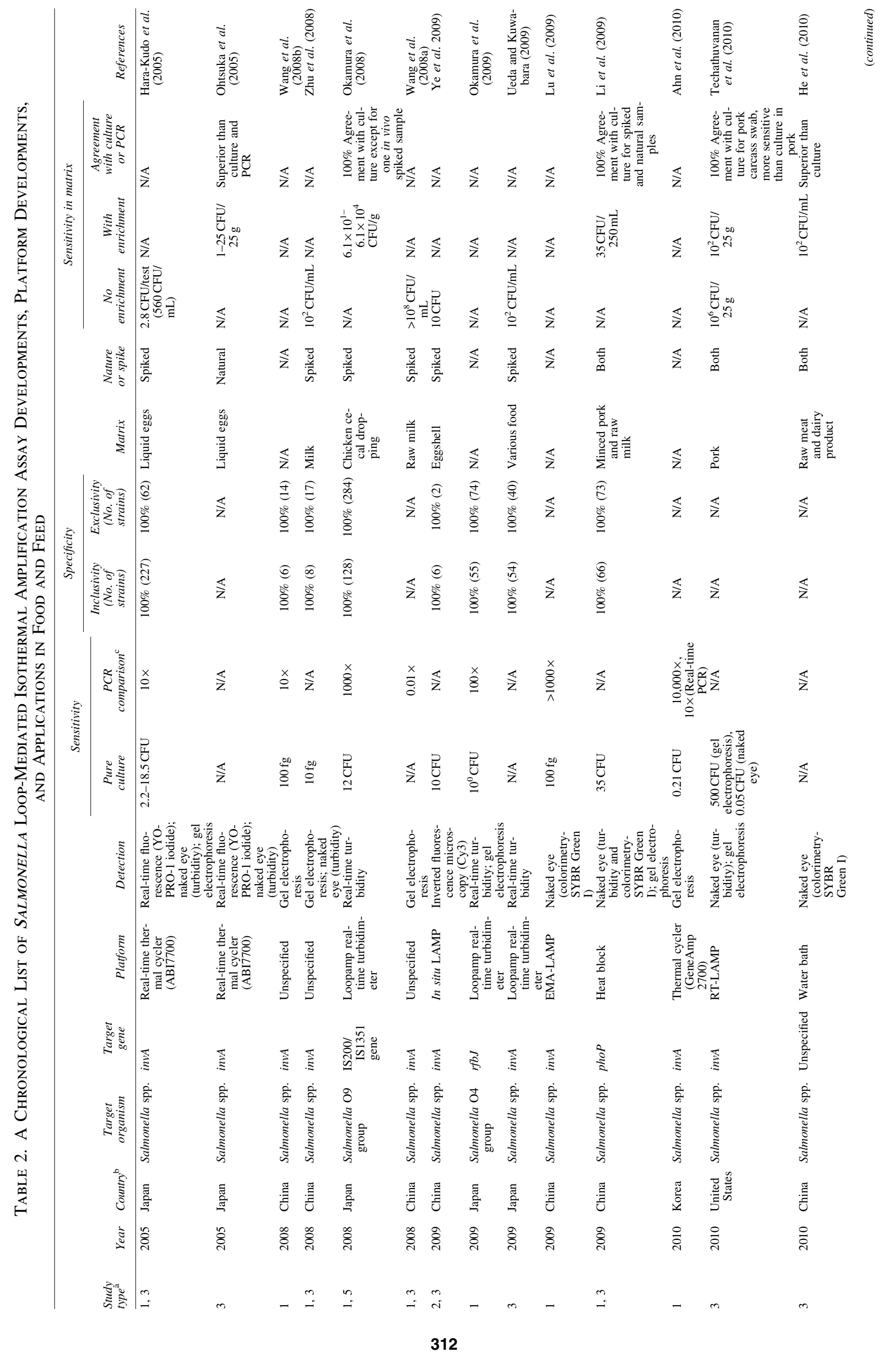




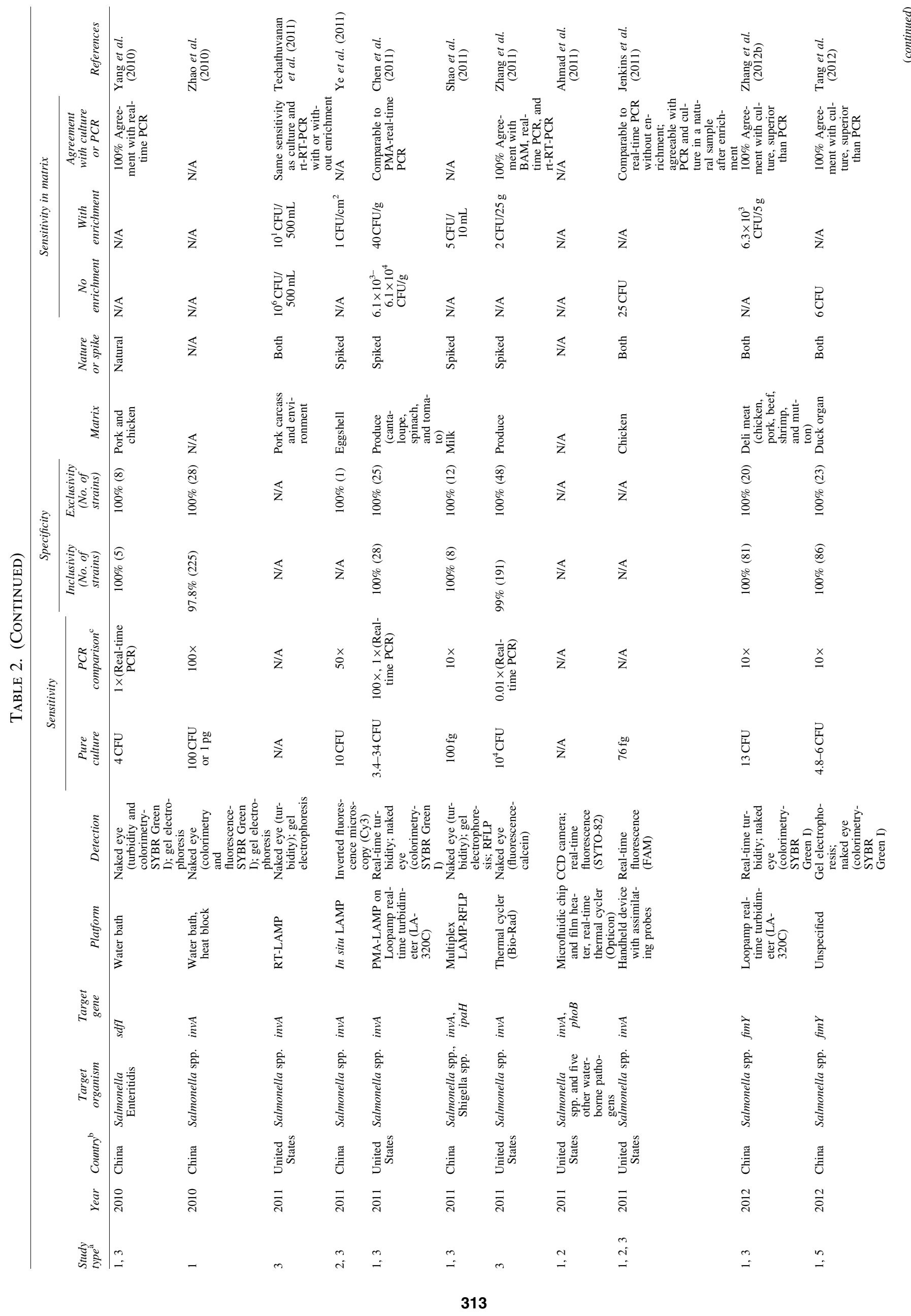




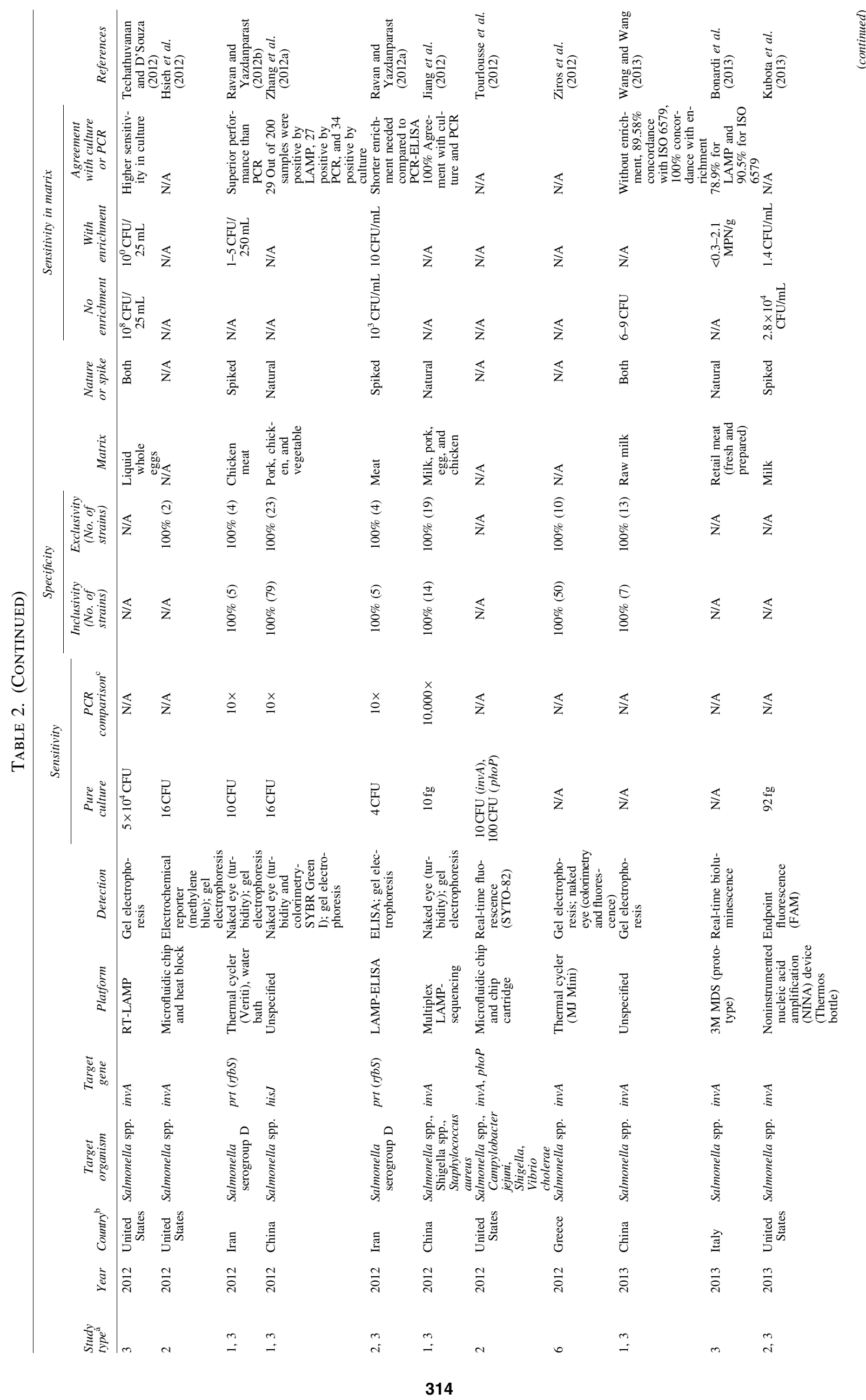




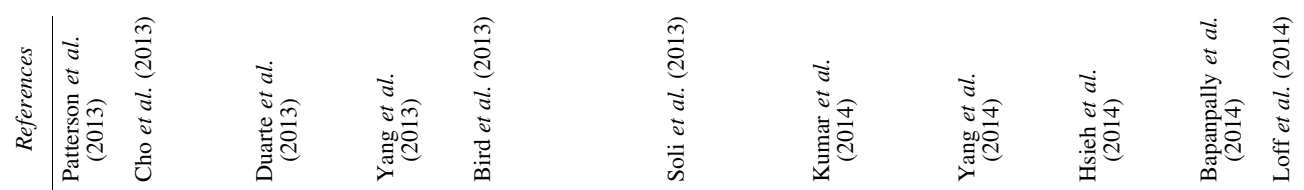

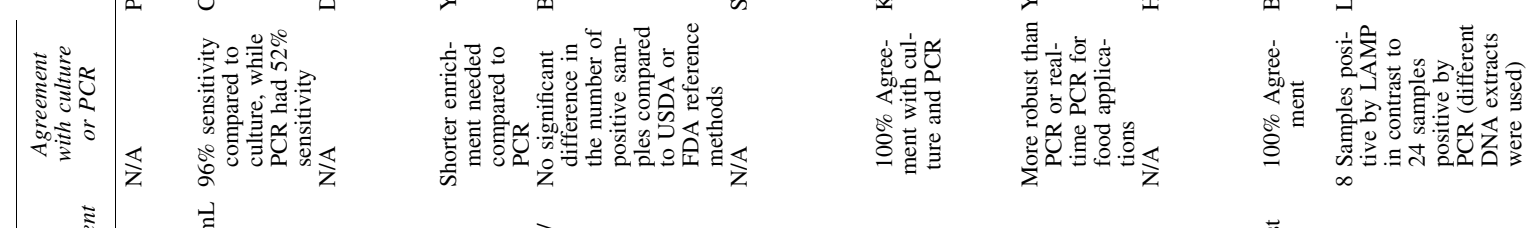

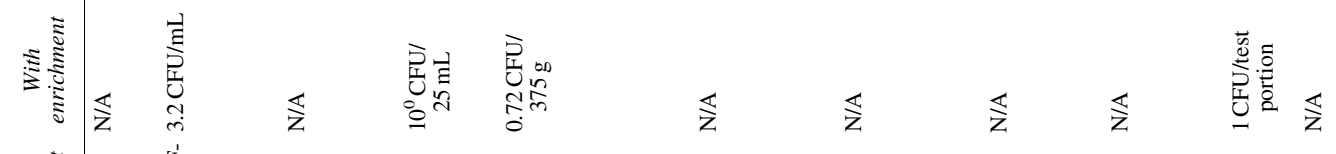

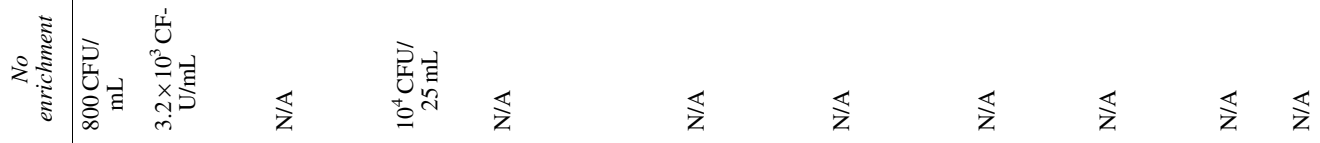

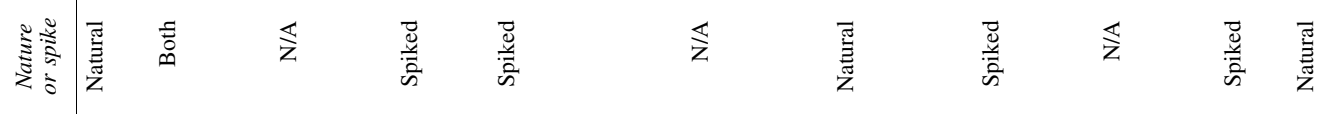

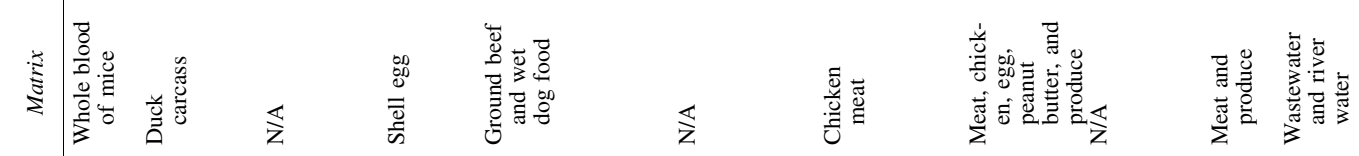

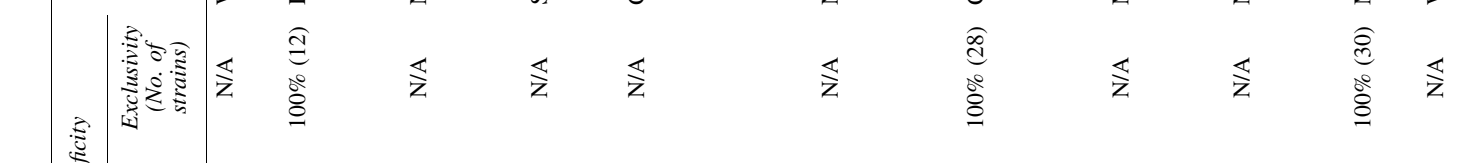

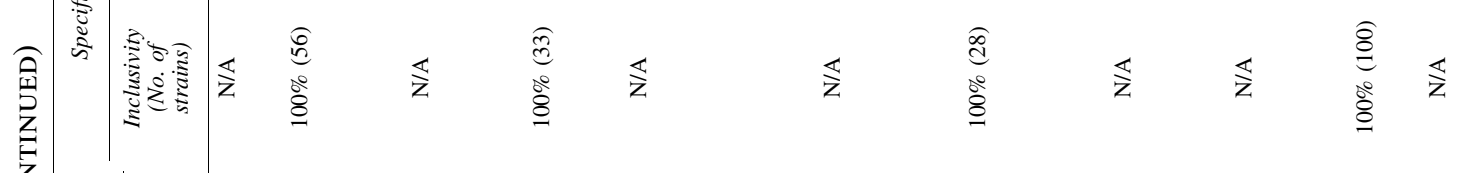

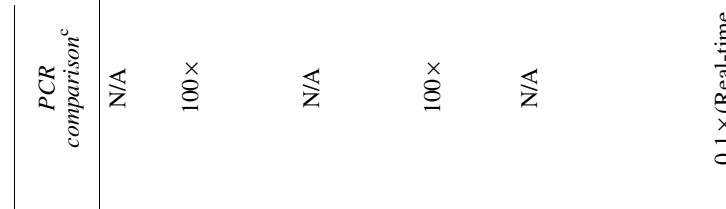

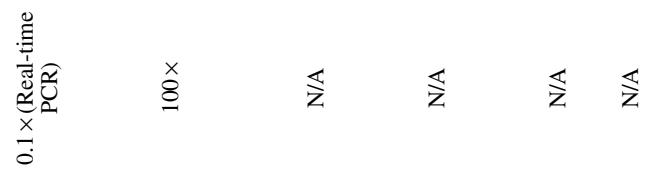

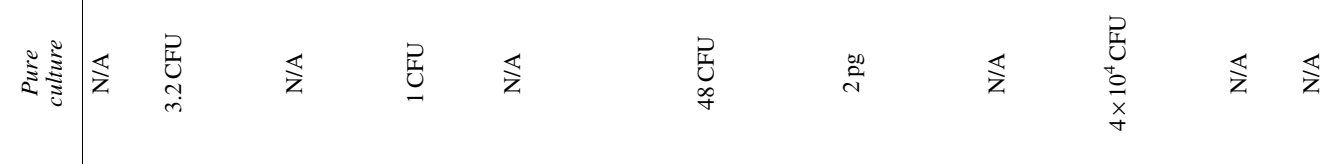

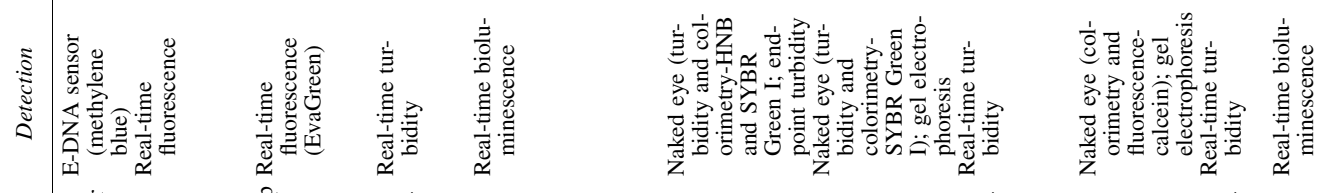

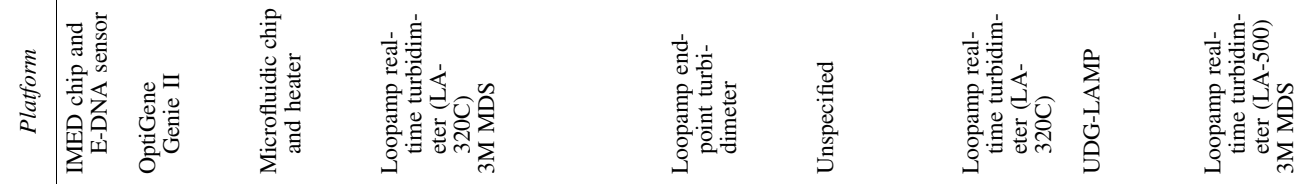

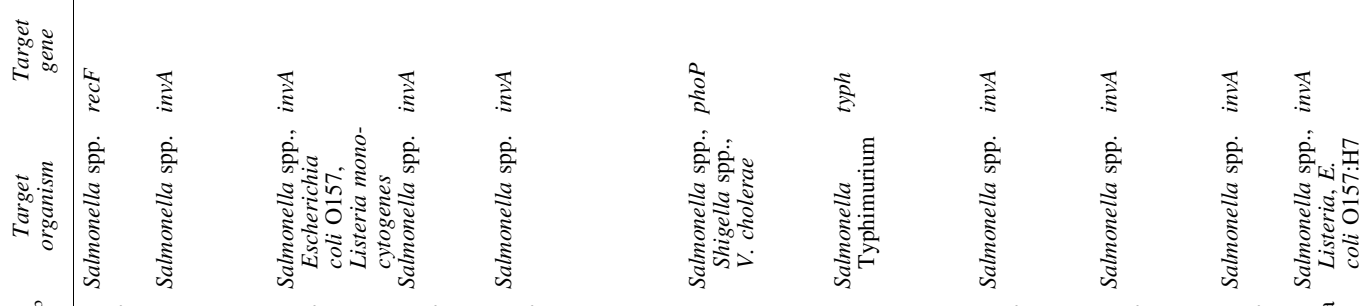

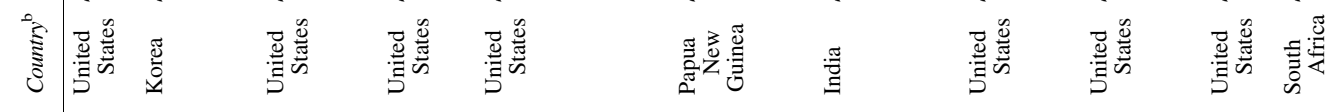

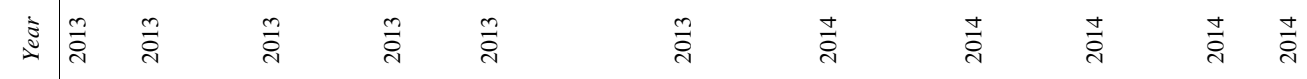

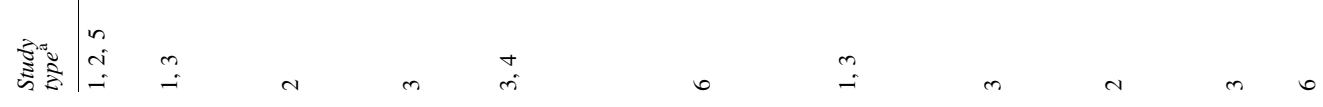




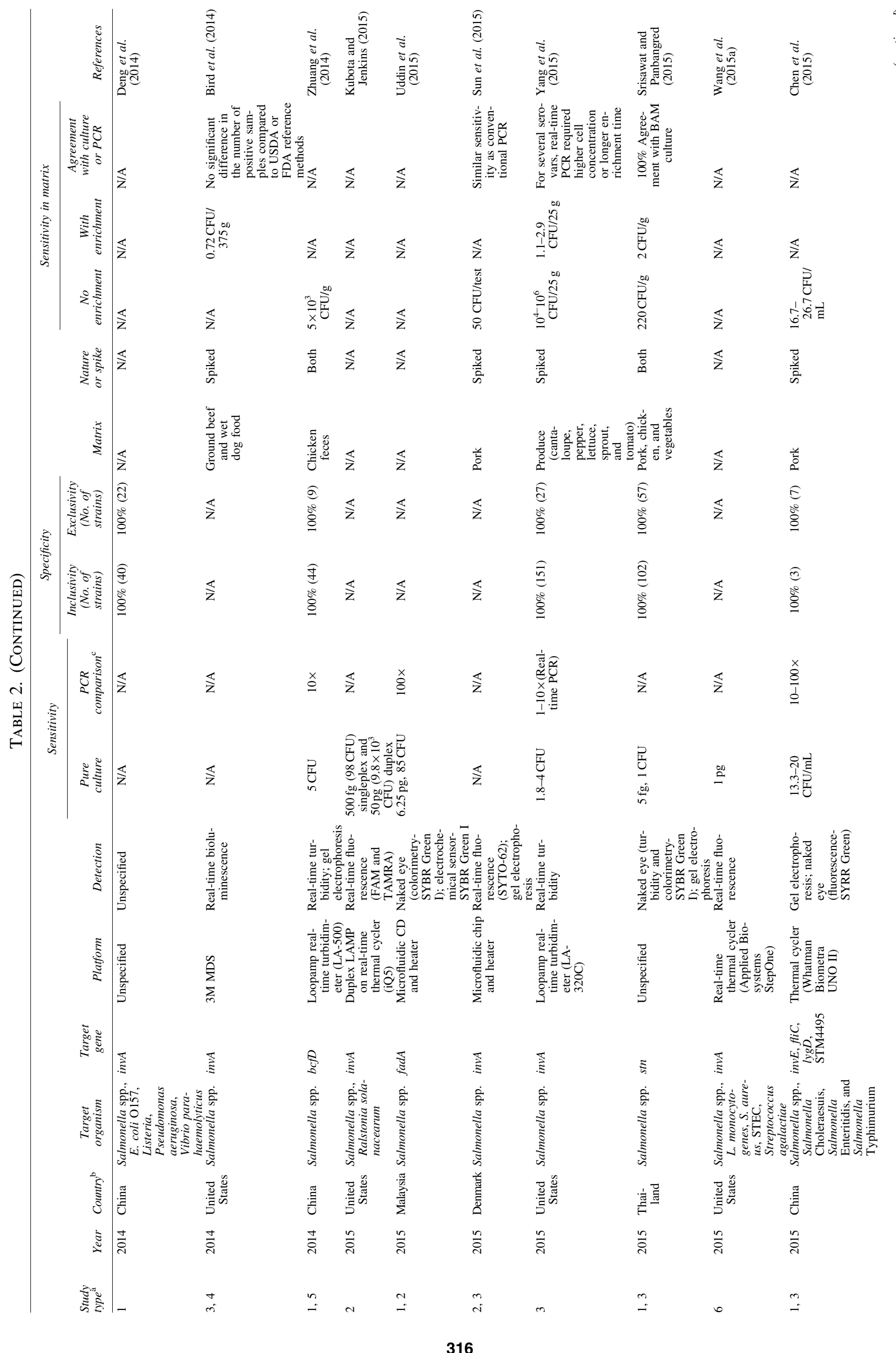




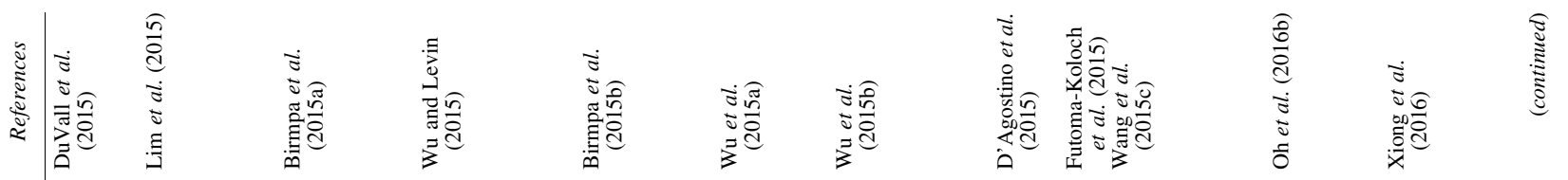

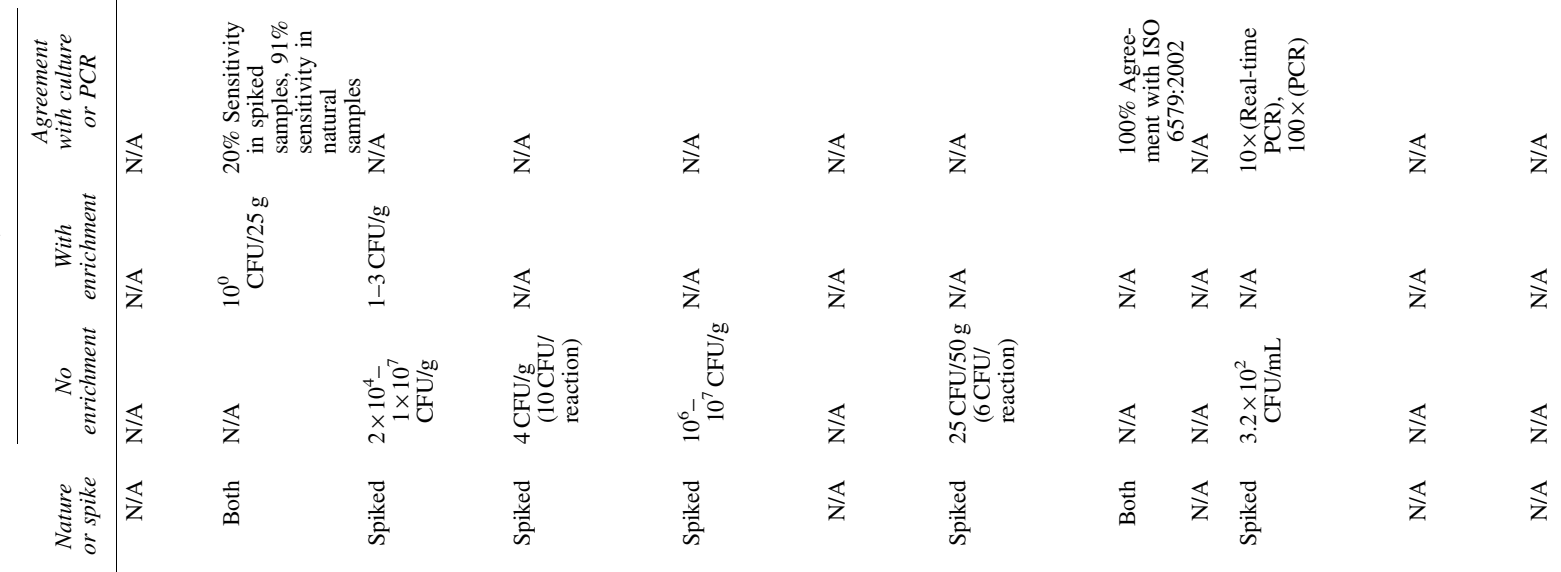

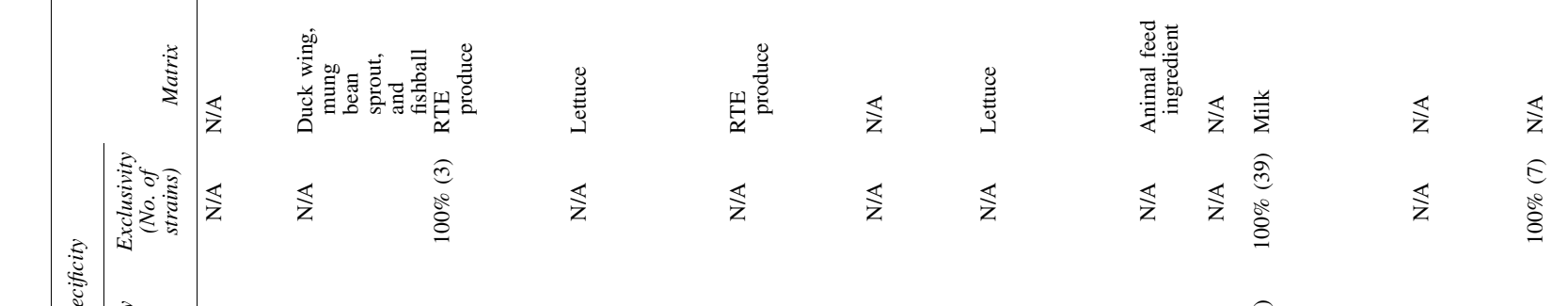

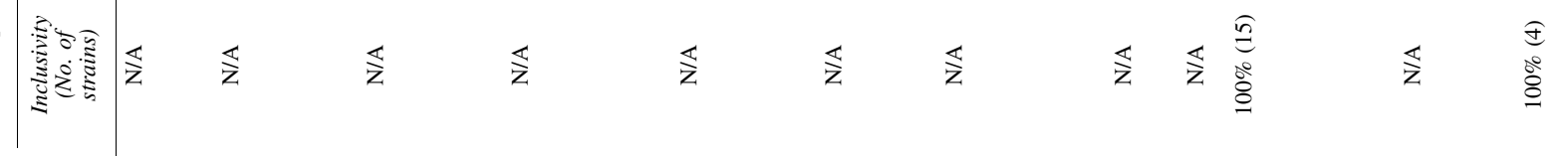

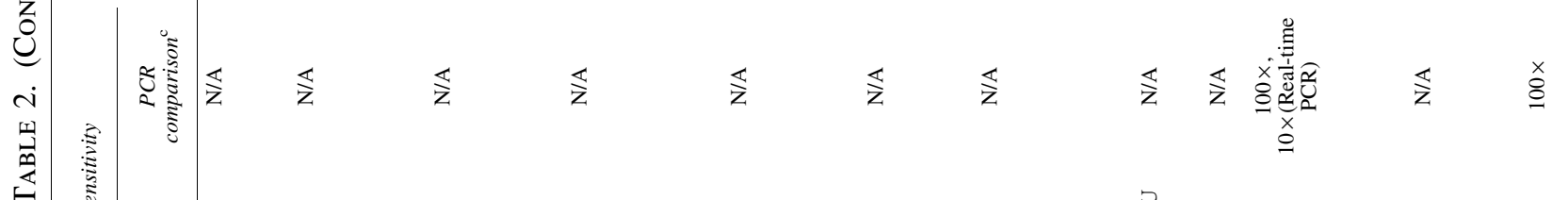

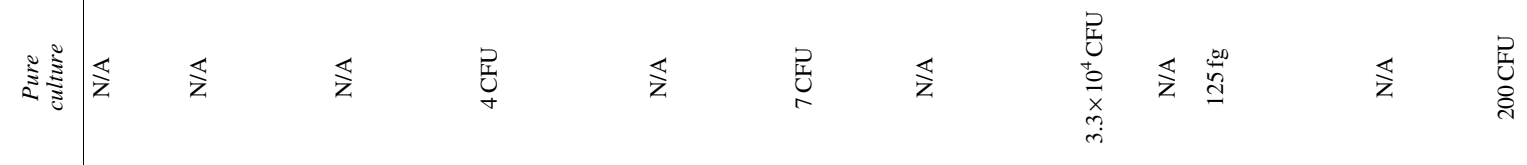

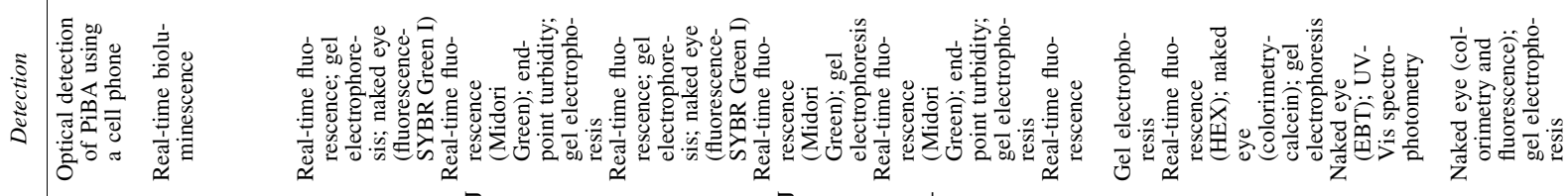

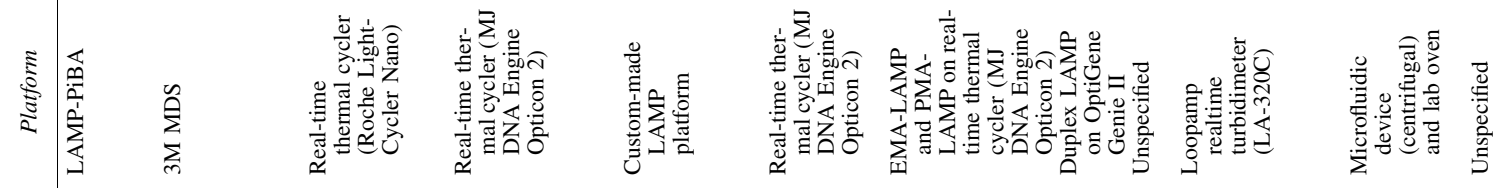

nt

艺

HIV

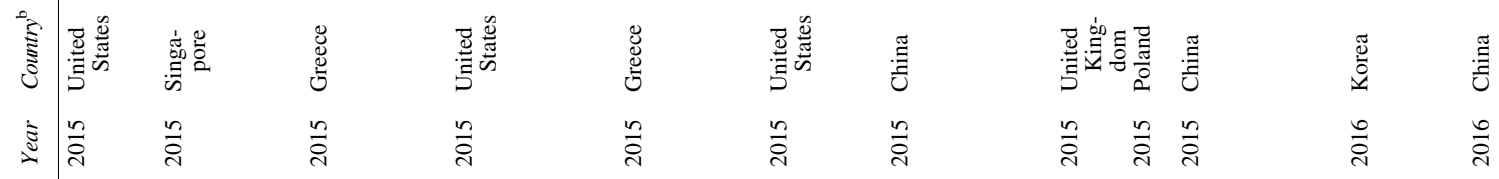

骨。 


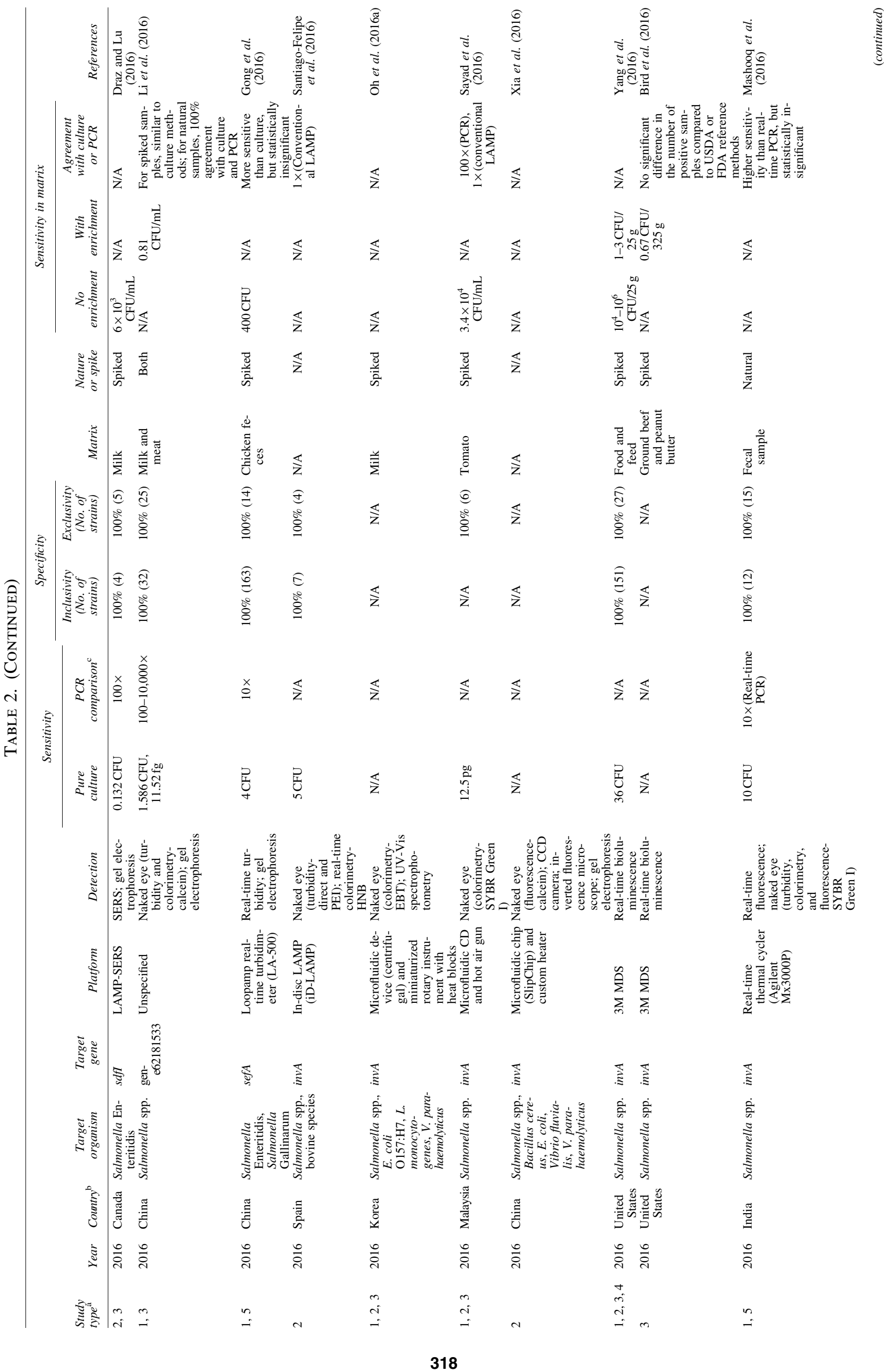




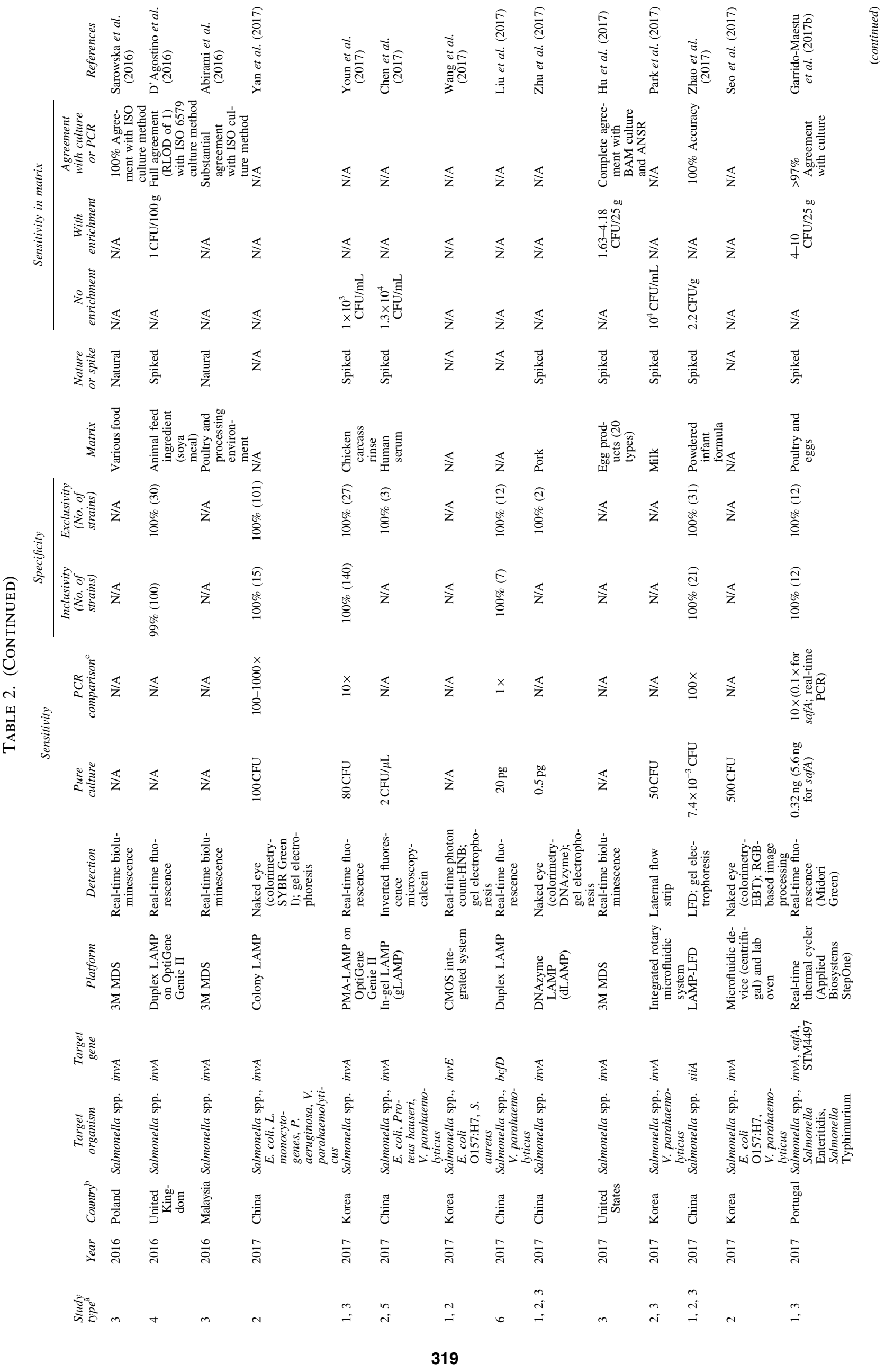




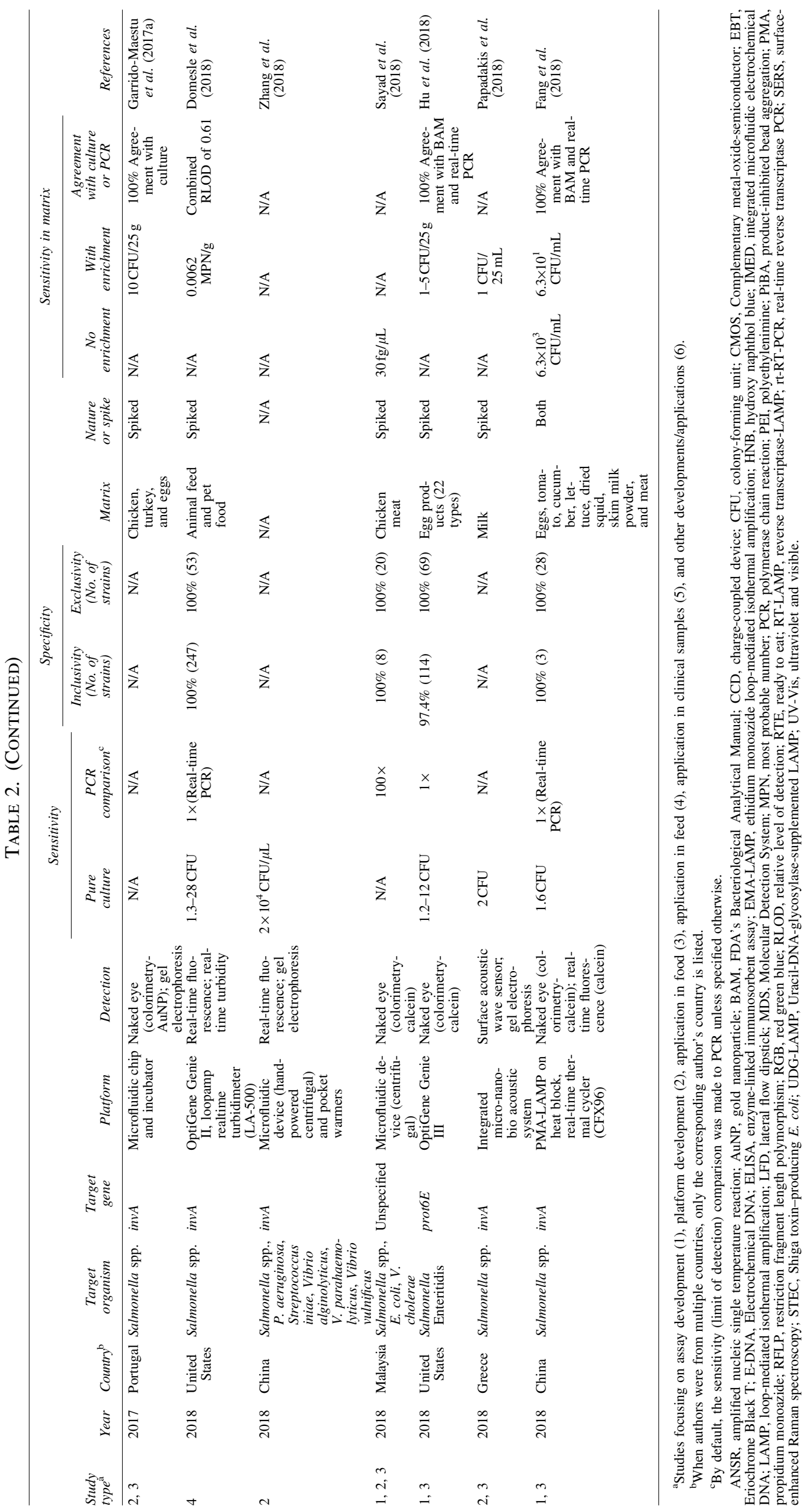


481 TCAGAACGTGTCGCGGAAGTCGCGGCCCGATTTTCTCTGGATGGTATGCCCGGTAAACAG 540 F3 $\rightarrow$ F2 $\rightarrow$ GTC

541 ATGAGTATTGATGCCGATTTGAAGGCCGGTATTATTGATGCGGATGCCGCGCGCGAACGG 600 TACTCATAACTACGGCTAAACT $\leftarrow$ LF ATAACTACGCCTACGGCGCGB1c $\rightarrow$ $\leftarrow$ F1c

601 CGAAGCGTACTGGAAAGGGAAAGCCAGCTTTACGGTTCCTTTGACGGTGCGATGAAGTTT 660 LB $\rightarrow$ CAAGGAAACTGCCACGCT $\leftarrow$ B2

661 ATCAAAGGTGACGCTATTGCCGGCATCATTATTATCTTTGTGAACTTTATTGGCGGTATT 720 TTCCACTGCGATAACGGC

$\leftarrow$ B3

Sal4 primers:

F3 $\left(5^{\prime}-3^{\prime}\right)$ : GAACGTGTCGCGGAAGTC

B3 $\left(5^{\prime}-3^{\prime}\right)$ : CGGCAATAGCGTCACCTT

FIP (F1c + $\underline{\text { F2 } ; ~ 5 '-3 '): ~ G C G C G G C A T C C G C A T C A A T A-T C T G G A T G G T A T G C C C G G ~}$

BIP (B1c + $\underline{\left.\text { B2 } ; 5^{\prime}-3^{\prime}\right): \text { GCGAACGGCGAAGCGTACTG-TCGCACCGTCAAAGGAAC }}$ LF $\left(5^{\prime}-3^{\prime}\right)$ : TCAAATCGGCATCAATACTCATCTG LB (5'-3'): AAAGGGAAAGCCAGCTTTACG

FIG. 2. A sequence alignment to illustrate the positions of six LAMP primers (F3, B3, FIP, BIP, LF, and LB) on the target gene. Partial nucleotide sequence of the Salmonella invasion gene invA (GenBank accession No. M90846) is shown, which was the target gene used to design our Salmonella LAMP assay (Yang et al., 2016). F3 and B3 are the forward and backward outer primers, respectively. FIP/BIP consists of complementary sequences of F1c/B1c and F2/B2 regions. BIP, backward inner primer; FIP, forward inner primer; LAMP, loop-mediated isothermal amplification; LB, loop backward; LF, loop forward.

lateral flow dipstick (LFD), and enzyme-linked immunosorbent assay (ELISA). Among them, detection by turbidity derived from magnesium pyrophosphate formation (white precipitate) has been the cornerstone of the LAMP technology (Mori et al., 2001).

Recently, we have seen explosive growth in the development and commercialization of LAMP-based microchips and microdevices for POC molecular diagnostics, many using optical and electrochemical methods (Safavieh et al., 2016). Some platforms are geared toward endpoint detection, while others focus on real-time detection. Given the large amount of DNA (10-20 $\mu \mathrm{g} / 25 \mu \mathrm{L}$ reaction mix) generated in a LAMP run (Kokkinos et al., 2014), platforms that allow closedtube detection are highly recommended to prevent crosscontamination.

As shown in Table 2, various platforms/methods have been developed for or adopted by Salmonella LAMP assays over the years. Figure 3 illustrates several examples of the monitoring methods used. In earlier studies, Salmonella LAMP reactions were run in water baths, heat blocks, or thermal cyclers, and detected by naked eye and gel electrophoresis (Table 2). Naked eye monitoring was generally performed in three ways (Zhang et al., 2014): first by observing the white precipitate (turbidity) formed in a LAMP reaction tube (Fig. 3a, top), second by observing the color change postamplification after adding DNA-binding dyes such as SYBR Green I, either under normal air (colorimetry) or ultraviolet (fluorescence) (Fig. 3a, middle), and third by observing the color change or fluorescence in the LAMP reaction tube with metal indicators (e.g., calcein and hydroxy naphthol blue [HNB]) added during assay preparation (Fig. 3a, bottom). Gel electrophoresis was done postamplification by running an agarose gel and observing the characteristic ladder-like banding pattern of LAMP amplicons (Fig. 3b). Despite being widely used, concerns of introducing ambiguity (in the case of naked eye) or contamination (for gel electrophoresis) render these methods less desirable (Zhang et al., 2014).

Real-time turbidity and real-time fluorescence have gained wide popularity as closed-tube or "one-pot" monitoring methods for Salmonella LAMP, especially with the recent availability of small, portable, robust, and user-friendly instruments (Fig. 1). As the LAMP reaction proceeds, turbidity or fluorescence readings are displayed in real time (amplification curves) and corresponding derivative values are plotted automatically at the completion of the run (derivative curves) (Fig. 3c, d). Results are interpreted based on whether these derivative values have reached thresholds set by the machine or user. While no modification to the LAMP reaction mix is needed for turbidity monitoring, to enable fluorescence detection, fluorophores are usually incorporated into the reaction mix or primers.

For turbidimetry-based Salmonella LAMP assays, Loopamp Realtime Turbidimeters LA-320 and LA-500 are commonly used platforms, whereas real-time PCR machines and Genie II have been used to develop several fluorescencebased Salmonella LAMP assays (Table 2). It is noteworthy that on the Genie II platform, an anneal step (from $98^{\circ} \mathrm{C}$ to $80^{\circ} \mathrm{C}$ with $0.05^{\circ} \mathrm{C}$ decrement per second) is included in each run to determine the annealing temperature of LAMP amplicons, which serves as an extra specificity check (Fig. 3d, bottom). Another closed-tube method used recently to monitor Salmonella LAMP reactions is based on bioluminescent assay in real time (BART) (Bird et al., 2013, 2014, 2016; Yang et al., 2016) (Fig. 3e) and performed in small platforms 

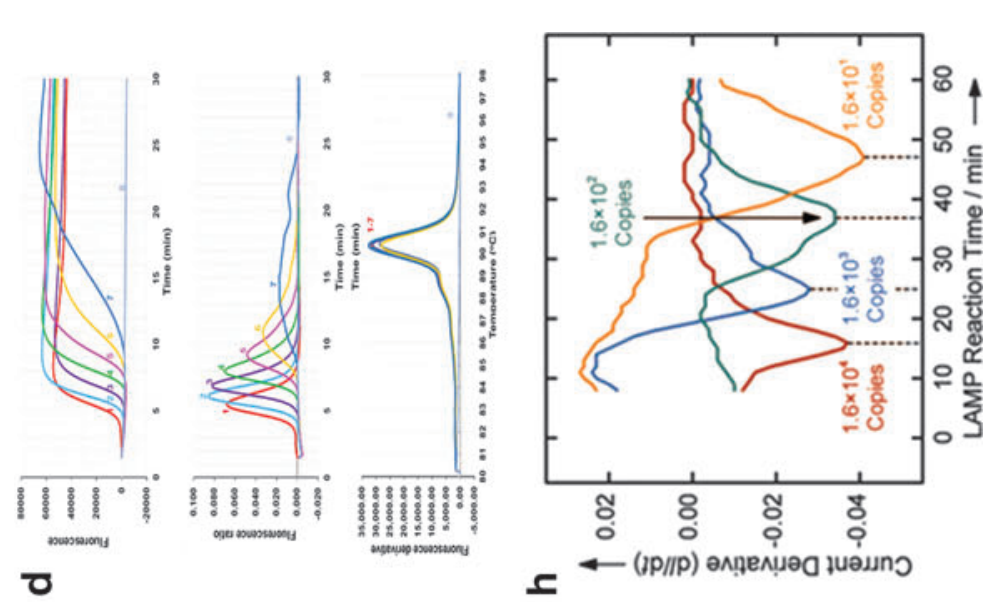

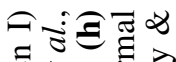

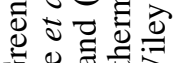

उ인

음

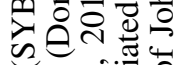

宅す்

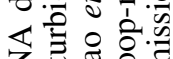

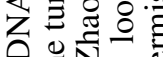

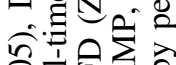

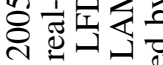

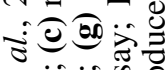

ธิ人ิิ) 유웜
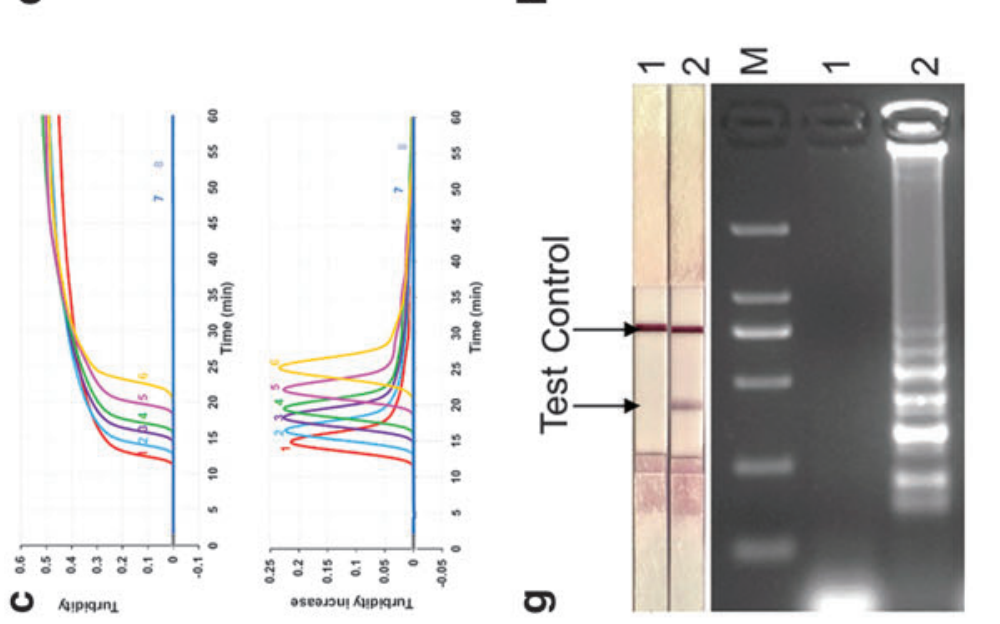
च்

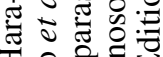

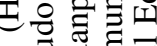

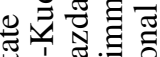

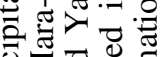
可记光 a.

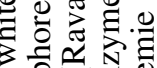
ธ。

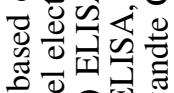

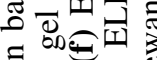

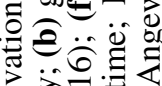
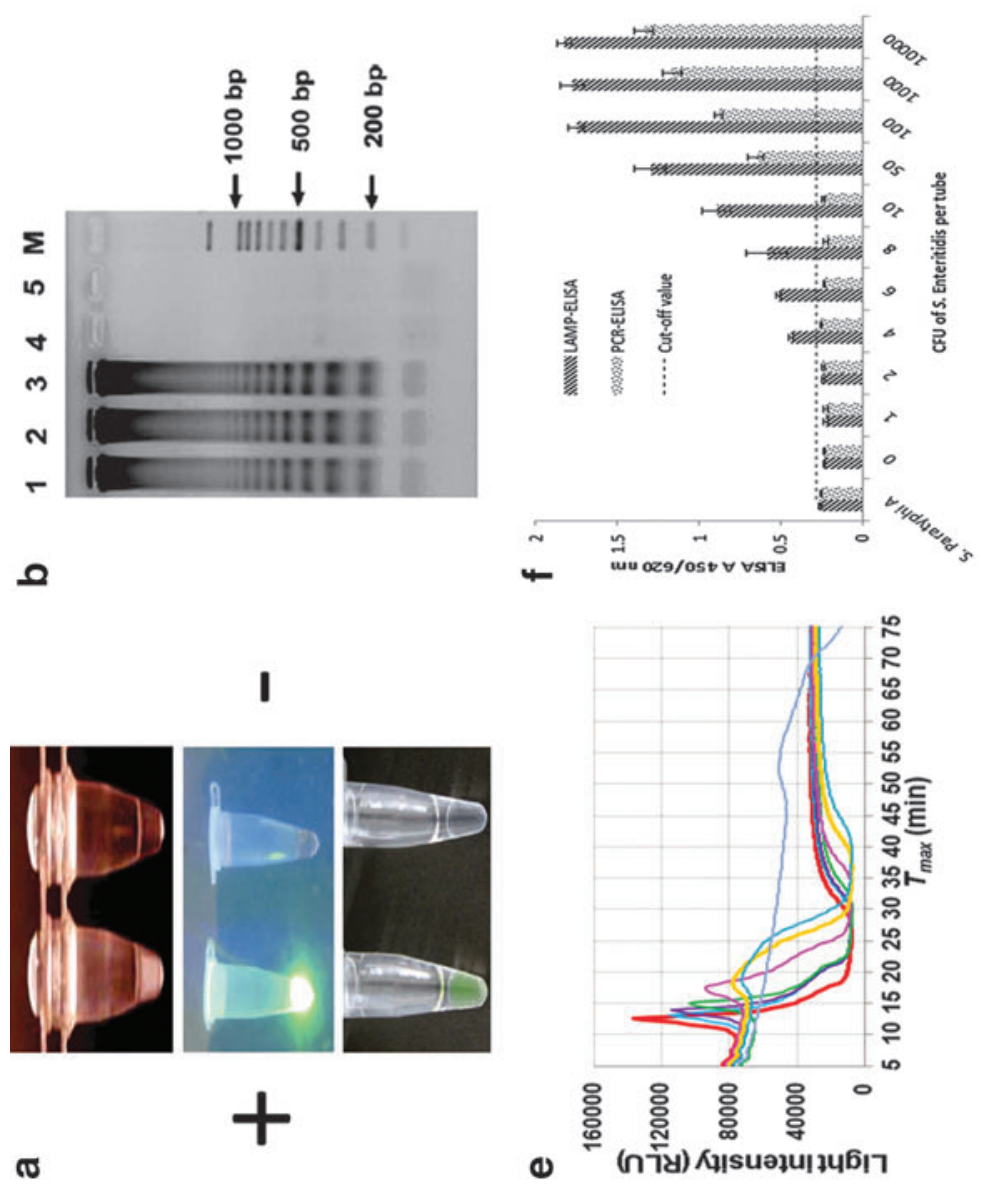

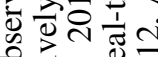

००

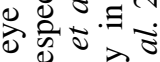

实

훈

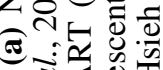
额部 。ัษฮี @司

皇

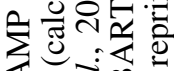

उच

氜

造运江

○.气

g

क융 둴

원

政

60

율 छ

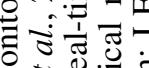

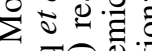

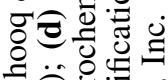

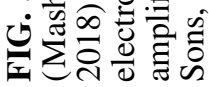


such as the 3M Molecular Detection System (MDS) (Fig. 1g). BART monitors the dynamic changes in the level of pyrophosphate produced in a LAMP reaction, which is converted to adenosine triphosphate (ATP) and utilized by firefly luciferase to emit light (Gandelman et al., 2010).

Several platforms also pair Salmonella LAMP assays with other novel detection methods downstream. Referred to as "open-tube" reactions, the process involves transferring LAMP amplicons to a second tube or platform for endpoint detection. Ravan and Yazdanparast (2012a) developed a LAMP-ELISA to detect Salmonella serogroup D by generating digoxigenin-labeled LAMP amplicons followed by hybridization to serogroup-specific oligonucleotide probes coated on a microtiter plate and ELISA readout (Fig. 3f). Draz and Lu (2016) combined LAMP with surface-enhanced Raman spectroscopy (LAMP-SERS) for the specific detection of Salmonella Enteritidis. To enable SERS detection, LAMP amplicons were hybridized with Raman-active Aunanoprobes followed by nuclease digestion and washes (Draz and $\mathrm{Lu}, 2016$ ).

More recently, Zhao et al. (2017) explored LFD as a new detection method for Salmonella LAMP (LAMP-LFD) (Fig. 3g). The LAMP FIP and BIP primers were labeled at the $5^{\prime}$ end with biotin and fluorescein isothiocyanate (FITC), respectively. Gold nanoparticles conjugated with anti-FITC antibody were embedded in the conjugate pad during the LFD assembly, whereas streptavidin and anti-mouse secondary antibody were added on the detection region to form the test line and control line, respectively. LAMP amplicons were mixed with a running buffer followed by LFD immersion into the mixture for detection. Noticeably, these opentube platforms require extensive postamplification manipulations, which are cumbersome, time-consuming, and prone to cross-contamination.

Recently, there have been many LAMP-based microfluidic devices designed for POC and food applications; some have used Salmonella as the model organism to show proof of concept (Table 2). For instance, Hsieh et al. (2012) designed a microfluidic electrochemical quantitative LAMP (MEQLAMP) chip (Fig. 4a) that used integrated electrodes to monitor the intercalation of DNA binding dye methylene blue redox reporter molecules into LAMP amplicons in real time. LAMP amplification was correlated with a decrease in the measured current signals (shown in Fig. 3h). Sun et al. (2015) developed an eight-chamber lab-on-a-chip (LOC) system (Fig. 4b) with integrated magnetic bead-based sample preparation and parallel LAMP amplification for Salmonella detection in food. After evaluating several DNA binding dyes, SYTO-62 was chosen for on-chip real-time fluorescence detection. Santiago-Felipe et al. (2016) designed a compact disc microreactor for LAMP (in-disc LAMP, iDLAMP) (Fig. 4c) and tested Salmonella as proof-of-concept; the reaction was monitored through HNB colorimetry.

Park et al. (2017) integrated DNA extraction, LAMP, and colorimetric lateral flow strip into a rotary microfluidic system (Fig. 4d) and demonstrated the parallel detection of Salmonella and Vibrio parahaemolyticus in milk. Very recently, Sayad et al. (2018) developed a centrifugal microfluidic platform (Fig. 4e) by incorporating a calcein-mediated colorimetric and wireless detection method for the parallel detection of E. coli, Salmonella, and Vibrio cholerae in food. Zhang et al. (2018) reported another centrifugal microfluidic platform (Fig. 4f) for parallel detection of six pathogens, Salmonella included, in a hand-powered, electricity-free format. The entire procedure, including nucleic acid purification, LAMP amplification, and visual detection of calceinbased fluorescence signals, is integrated into a microfluidic disc, achieving sample-to-result POC diagnostics (Zhang et al., 2018).

\section{Assay optimization}

Attempts to optimize LAMP reagent mix and/or reaction condition have been made in several Salmonella LAMP studies. Upon optimizing all components of a newly developed Salmonella LAMP assay, Chen et al. (2011) concluded that eliminating betaine from the LAMP reagent mix resulted in shorter time-to-positive results and stronger turbidity signals, that is, better amplification efficiency. In another study, the addition of betaine also contributed to a reduction in the amount of LAMP amplicons (Li et al., 2016), whereas Garrido-Maestu et al., (2017b) reported that with betaine, false positive results were generated from nontarget DNA as well as water. Instead, the addition of dimethyl sulfoxide (DMSO) at $7.5 \%$ was found to be favorable for LAMP amplification (Garrido-Maestu et al., 2017b).

Multiple Salmonella LAMP studies have confirmed that the incorporation of loop primers significantly decreased the time taken to obtain positive results, often by $20 \mathrm{~min}$ or more (Okamura et al., 2009; Zhuang et al., 2014; Mashooq et al., 2016). The reaction time for Salmonella LAMP assays ranges from $25 \mathrm{~min}$ to $2 \mathrm{~h}$, and those requiring $>60 \mathrm{~min}$ usually lacked loop primers (Ye et al., 2011). Running temperatures for the assays fall between $60^{\circ} \mathrm{C}$ and $65^{\circ} \mathrm{C}$, except that $66^{\circ} \mathrm{C}$ was used in three studies (Gong et al., 2016; Park et al., 2017; Seo et al., 2017).

\section{Assay evaluation}

Specificity (inclusivity and exclusivity) and sensitivity (pure culture/DNA and comparison with PCR) evaluations of newly developed Salmonella LAMP assays are usually performed at the time of initial assay development. Unfortunately, these key parameters are missing for quite a few studies, especially those focusing on proof-of-concept POC diagnostics. As shown in Table 2, the number of strains tested for inclusivity (range, 3-247) and exclusivity (range, 1-284) varies vastly among the studies. Many studies did not meet the recommendations of AOAC International (AOAC, 2012) and the International Organization for Standardization (ISO, 2016) on testing at least 100 Salmonella strains of different serovars for inclusivity and at least 30 competitive strains for exclusivity. Although strains belonging to S. enterica subsp. enterica (I) are well represented in inclusivity testing, those belonging to five other subspecies of $S$. enterica (i.e., salamae [II], arizonae [IIIa], diarizonae [IIIb], houtenae [IV], and indica [VI]) and Salmonella bongori are seldom tested. Nonetheless, almost all studies uniformly reported $100 \%$ inclusivity and $100 \%$ exclusivity for respective Salmonella LAMP assays developed, highlighting the highly specific nature of the LAMP technology.

Zhang et al. (2011) reported that one S. enterica subsp. arizonae strain CNM-247 and one S. bongori strain 95-0321 failed to be amplified by the Hara-Kudo's primer sets, neither did one S. enterica subsp. arizonae strain NCTC 7301 in 

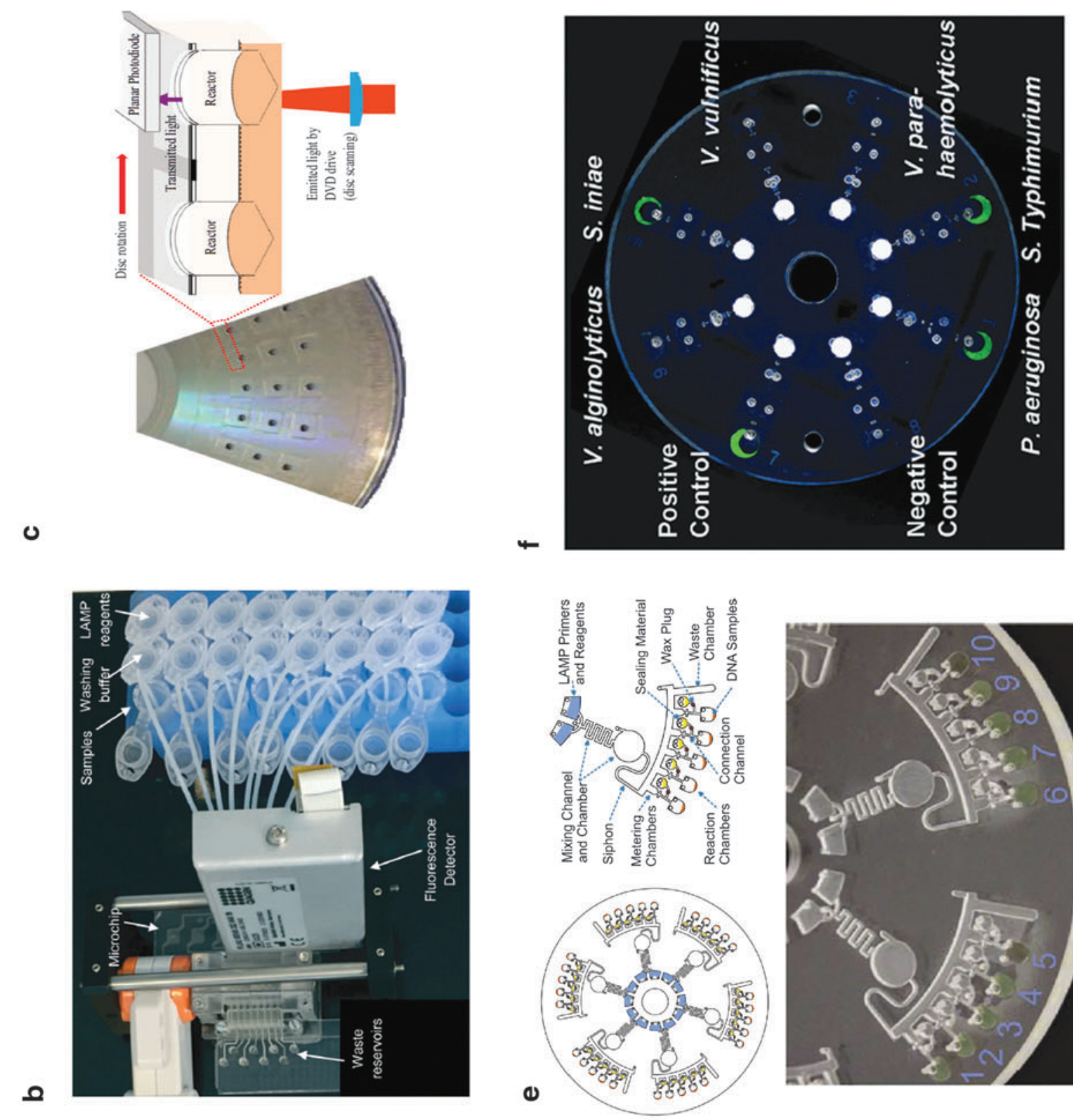

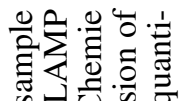

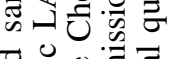

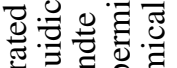

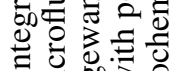
.ే.

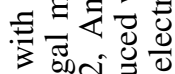

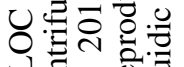
गें

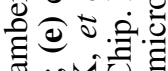
无记元

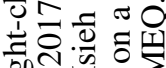
ब ใิ กิ่ তู류

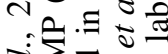

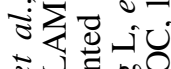
ธ.$\Xi 00$

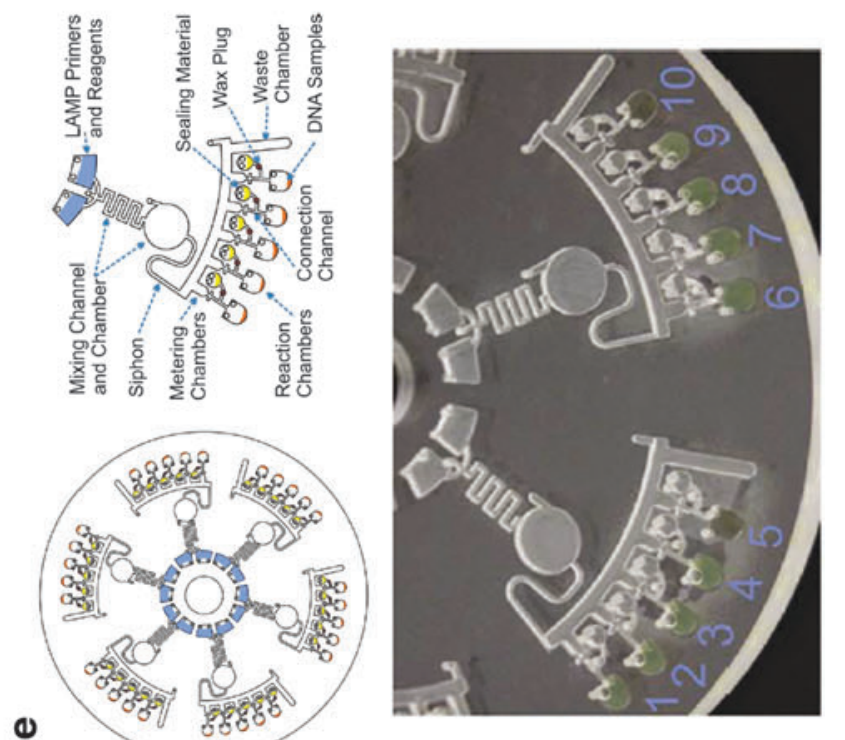

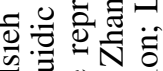

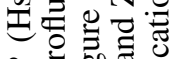

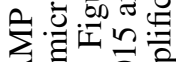
궁ㅎㅇ

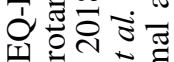
$\sum \overrightarrow{0}$

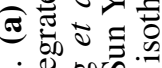

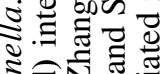
ఏิత్ర สิ 宅包

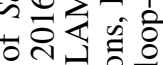
ฮี

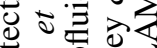
웡융. 힐

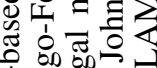
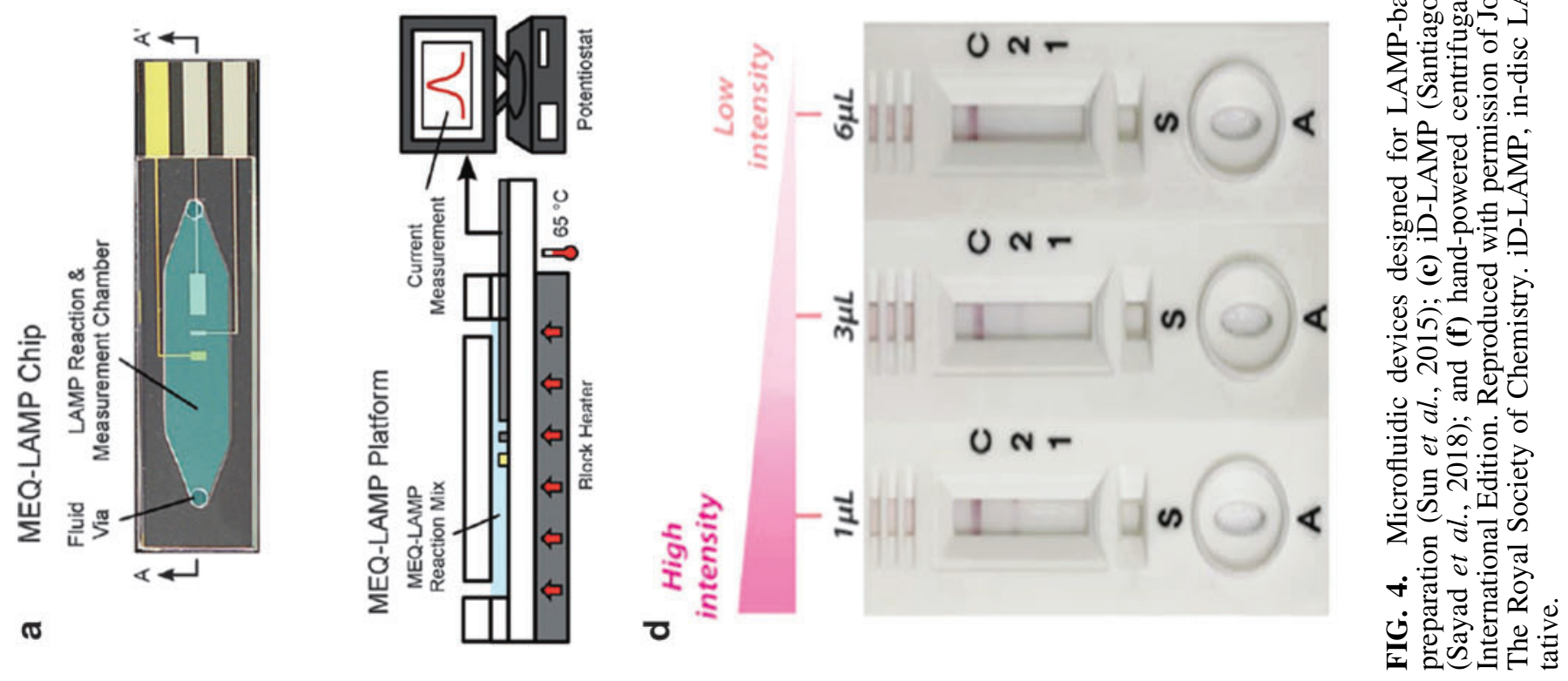
another study (D'Agostino et al., 2016), while successful amplification of seven $S$. enterica subsp. arizonae strains along with 220 S. enterica subsp. enterica strains of 39 serovars were shown at the time of assay development (HaraKudo et al., 2005). Very recently, Domesle et al. (2018) evaluated the specificity of our invA-based Salmonella LAMP assay (Yang et al., 2016) (Fig. 2) using 300 bacterial strains (247 Salmonella strains of 185 serovars and 53 nonSalmonella strains) and demonstrated $100 \%$ specificity on both turbidimetry- and fluorescence-based platforms. Eleven $S$. enterica subsp. arizonae strains were tested and when compared to those belonging to other $S$. enterica subspecies, significantly longer time-to-positive results were required for these $S$. enterica subsp. arizonae strains (Domesle et al., 2018).

In pure-culture sensitivity testing, the reported limits of detection for all Salmonella LAMP assays ranged from 0.132 to $5 \times 10^{4}$ colony-forming unit (CFU) per reaction with several reporting a level much lower than $1 \mathrm{CFU}$ (Table 2). Among studies where genomic DNA was tested, the limits of detection fell between $5 \mathrm{fg}$ and $5.6 \mathrm{ng}$ per reaction (Table 2). These are equivalent to a range from $1 \mathrm{CFU}$ to $1 \times 10^{6} \mathrm{CFU}$ per reaction, assuming one Salmonella genome weighs about 5 fg (Malorny et al., 2004). Numerous studies also compared the sensitivity between LAMP and PCR or real-time PCR (Table 2). The superior performance of LAMP (10- to 10,000 -fold better sensitivity) over PCR was observed in the majority of studies, while equal (Yang et al., 2010; Liu et al., 2017) or lower sensitivity (0.01-fold) of LAMP to PCR (Wang et al., 2008a) was also reported. On the other hand, real-time PCR had limits of detection rather comparable (within 10-fold difference) to LAMP (Table 2).

\section{Salmonella LAMP Assay Application}

Since 2008, the application of Salmonella LAMP assays in human food has expanded to numerous food matrices, such as chicken, turkey, pork, beef, produce, and milk. More recently, Salmonella LAMP assays have also been applied in animal food, that is, pet food, animal feed, and raw materials and ingredients (D'Agostino et al., 2015; Bird et al., 2016; Yang et al., 2016). Below we present some challenges commonly associated with foodborne pathogen detection and the promise that LAMP offers and some actual applications.

\section{Challenges and promises}

Salmonella detection in human and animal food faces many of the same inherent challenges associated with general food testing for pathogens (Ge and Meng, 2009; Wang et al., 2013). Food and feed encompass many diverse and complex matrices, which presents a major hurdle toward developing effective sample preparation and testing strategies. Many matrices frequently harbor inhibitors to key reagents used in molecular assays, such as PCR enzymes, which greatly undermine the efficiency and utility of such assays. The presence of high levels of background flora in some matrices may also interfere with assay performance. Therefore, matrixspecific assay evaluations may be necessary. Furthermore, Salmonella is usually present in food or feed at much lower concentrations than those found in clinical specimens and the bacterial cells may be injured by the processes used to produce the food or feed (Ge and Meng, 2009).
To address these challenges, enrichment is commonly used to resuscitate injured Salmonella cells, increase the concentration of Salmonella, and dilute the effect of inhibitors and background flora on the assays (Wang et al., 2013). This is a general strategy applied to improve pathogen detection in food and feed, which is not limited to LAMP.

One major advantage of LAMP over PCR is the high tolerance to biological substances, such as whole blood and urine, commonly found in clinical specimens (Kaneko et al., 2007; Yang et al., 2014). This advantage also translates into food testing for pathogens as a means to overcome matrix effects. We designed a study to specifically evaluate the robustness of a Salmonella LAMP assay for food applications (Yang et al., 2014). Besides superior performance over PCR under abusive $\mathrm{pH}$ conditions, LAMP also showed greater tolerance to potential assay inhibitors (e.g., humic acid, soil, and culture media) than PCR. When food rinses, including meat juice, chicken rinse, egg homogenate, and produce homogenate, were added at $20 \%$ of the reaction mix, PCR amplifications were completely inhibited, but LAMP reactions were not (Yang et al., 2014). The study highlights the promise of LAMP as a robust and powerful method for Salmonella detection in various food matrices.

\section{Application in food}

As shown in Table 2, Salmonella LAMP assays have been applied in a wide variety of food matrices, including all the major food categories linked to Salmonella outbreak-associated illnesses, for example, produce, eggs, chicken, pork, and beef (IFSAC, 2015, 2017). The most widely adopted assay (in 27 studies) is the one developed by Hara-Kudo et al. (2005) followed by Chen et al. (2011) in 6 studies. While most studies used spiked samples, naturally contaminated samples have been examined. Platforms adopted for these assays are similar to those used in assay development as are the amplicon detection methods (Table 2).

Without enrichment, the reported sensitivity varies greatly, ranging from $2.2 \mathrm{CFU} / \mathrm{g}$ to $10^{8} \mathrm{CFU} / \mathrm{mL}$ (Table 2). Enrichment ( $4 \mathrm{~h}$ to overnight) has been widely adopted and some studies reported probabilities of detection in lieu of limits of detection. The inclusion of an enrichment step clearly increased the ability of LAMP assays to detect Salmonella in food; many reported the successful detection of $<1 \mathrm{CFU}$ per test portion (in gram or $\mathrm{mL}$ ) analyzed (Table 2).

\section{Application in feed}

Six recent studies have described the application of Salmonella LAMP assays in animal food matrices (Table 2). Notably, the closed-tube Genie II platform for real-time fluorescence detection of LAMP amplicon uses an extra anneal step, which has been explored recently for duplex detection of two targets by using the distinct annealing temperatures of the LAMP products, as described by Liu et al. (2017) for the detection of Salmonella and V. parahaemolyticus and by D'Agostino et al. (2015) for the detection of Salmonella and an internal amplification control (IAC). In the latter study, the IAC sequence was designed so that it could be amplified by the same primer set for Salmonella, but with increased G:C content, thereby increasing the annealing temperature of the IAC amplicon by $1.6^{\circ} \mathrm{C}$. The assay sensitivity, however, was reduced by 1,000 -fold with 
the IAC (D'Agostino et al., 2015). Nonetheless, the ability to incorporate an IAC is especially useful when applying Salmonella LAMP assays in animal food, since it takes longer time to reach positive results in animal food compared to human food, suggesting matrix effects are more pronounced in these matrices (Yang et al., 2016). As in human food applications, with enrichment, Salmonella LAMP assays could detect a few CFUs per animal food portion analyzed (Table 2).

\section{Validation studies}

Method validation is a critical step before a new method can be adopted for routine use. Despite growing applications of Salmonella LAMP assays in food and feed matrices (Table 2), limited effort has been put forth to validate the assay performance against well-established reference methods following international guidelines (AOAC, 2012; ISO, 2016). These validation studies, performed at single laboratory, independent laboratory, and collaborative study (interlaboratory) levels, present rigorous opportunities to test an assay's inclusivity/exclusivity, sensitivity, and probability of detection in a food or feed matrix (AOAC, 2012; ISO, 2016). For instance, in a dog food matrix study, bulk samples are inoculated at low (0.2-2 CFU/25 g) and high (2-10 CFU/ $25 \mathrm{~g})$ concentrations, mixed well, and aged for at least 2 weeks to best mimic a natural contamination event (AOAC, 2012). The reference method and the alternative method are then applied to detect Salmonella using either a paired or unpaired study design (ISO, 2016).

In this context, validations of several commercially available Salmonella LAMP detection kits have been completed, including 3M MDA Salmonella in raw ground beef and wet dog food (Bird et al., 2013, 2014), 3M MDA 2Salmonella in raw ground beef and creamy peanut butter (Bird et al., 2016), and SAS Molecular Tests Salmonella Detection Kit in ground beef, beef trim, ground turkey, chicken carcass rinses, bagged mixed lettuce, and fresh spinach (Bapanpally et al., 2014). Among them, 3M MDA 2-Salmonella has been approved for Official Method of Analysis (OMA) by AOAC International (OMA method No. 2016.01).

It is noteworthy that two Salmonella LAMP assays geared toward applications in animal food have moved forward with such validation efforts. D'Agostino et al. (2016) described the validation of a LAMP/ISO 6579-based method for analyzing soya meal (an animal feed ingredient) for the presence of Salmonella spp. through an interlaboratory trial. The alternative method achieved the same percentage correct identification (full agreement) as the reference method, demonstrating its suitability for adoption as a rapid method for identifying Salmonella in this matrix. In another study (Domesle et al., 2018), we reported the validation of our invA-based Salmonella LAMP assay in multiple animal feed and pet food items by closely following the guidelines (AOAC, 2012; FDA, 2015; ISO, 2016). Compared to the reference method, the relative levels of detection for all animal food items fell within the acceptability limits for an unpaired study (Domesle et al., 2018).

\section{Future Perspectives}

In this review, we summarized 100 articles published around the globe between 2005 and 2018 on the development and application of Salmonella LAMP assays in various food and feed matrices (Table 2). LAMP has clearly established itself as a powerful alternative to PCR for the rapid, reliable, and robust detection of Salmonella, with several assays already successfully validated through multilaboratory studies in specific food and feed matrices.

It is a high possibility that scientific and commercial advancements in the LAMP technology, in general, will propel and shape future developments in this field. This includes the development of new LAMP reagents and new platforms to further capitalize on the two most distinctive characteristics of LAMP, that is, rapidity and simplicity (Mori et al., 2013). Already, we have seen many recent developments in new LAMP reagents, particularly enzymes and master mixes, for example, Bst 2.0 and Bst 2.0 WarmStart DNA polymerases (New England Biolabs, Ipswich, MA), GspSSD and Tin DNA polymerases and isothermal master mixes (OptiGene Ltd., West Sussex, United Kingdom), and OmniAmp DNA polymerase and LavaLAMP master mixes (Lucigen Corporation, Middleton, WI), which offer better thermostability, higher amplification efficiency, and are thus more amenable to resource-limited and field conditions. Positive results may be obtained within 5 min using some of these reagents. Lyophilized LAMP reagents have been commercialized for some clinical diagnostic kits (Mori et al., 2013), a reagent format that may be adopted by Salmonella LAMP detection kits for food and feed in the future.

Multiplex LAMP assays are just beginning to be explored (Mayboroda et al., 2018), using release of quenching technology (Tanner et al., 2012), fluorogenic hybridization (Nyan and Swinson, 2015), endonuclease restriction (Wang et al., 2015), assimilating probes (Kubota and Jenkins, 2015), and annealing temperature differentiation (D'Agostino et al., 2015; Liu et al., 2017) to detect multiple targets in a single reaction tube. The latter two techniques have been applied in Salmonella (D'Agostino et al., 2015; Kubota and Jenkins, 2015; Liu et al., 2017). These differ in principle from parallel detection described for many POC microfluidic devices where LAMP reactions for multiple targets are carried out in separate chambers or wells simultaneously. Future developments in chemistries/strategies for multiplex LAMP assays will greatly advance the multiplex LAMP detection of Salmonella (multiple genes or pathogens).

Regarding new platform developments, closed-tube, "onepot" platforms that allow rapid, sensitive, specific, and realtime amplification and detection in small, portable, robust, and user-friendly instruments will be the mainstream. The development and refinement of microfluidic devices (heat control, fluid manipulation, and monitoring method) will continue at a rather fast speed, focusing on full integration of sample preparation, amplification, and detection on one simple, small, user-friendly microdevice. Improvements in sample throughput and field amenability are also desired.

Special considerations should be given when adopting these new advancements in food and feed testing. In terms of assay development, there is currently a paucity of LAMP primers developed for specific Salmonella serovars other than Salmonella Enteritidis and Salmonella Typhimurium. LAMP assays for Salmonella serovars that are major animal pathogens are also scarce. Progresses in the areas of viable detection (Lu et al., 2009; Chen et al., 2011; Techathuvanan and D'Souza, 2012) and contamination prevention (Hsieh 
et al., 2014) have been made and further research is still needed. Simple and effective sample preparation methods, including DNA extraction and storage for field detection are in great demand. Further developments in noninstrumented nucleic acid amplification such as running the assays in a thermos (Kubota et al., 2013) or a pocket warmer (Zhang et al., 2018) will enable field-based food and agricultural diagnostics. Finally, there is an increasing need for matrixspecific validation of newly developed methods. Such validations should follow international guidelines before the methods can be adopted for routine use in food and feed testing.

Disclaimer: The views expressed in this article are those of the authors and do not necessarily reflect the official policy of the Department of Health and Human Services, the U.S. Food and Drug Administration, or the U.S. Government. Reference to any commercial materials, equipment, or process does not in any way constitute approval, endorsement, or recommendation by the Food and Drug Administration.

\section{Disclosure Statement}

No competing financial interests exist.

\section{References}

Abirami N, Nidaullah $\mathrm{H}$, Chuah LO, et al. Evaluation of commercial loop-mediated isothermal amplification based kit and ready-to-use plating system for detection of Salmonella in naturally contaminated poultry and their processing environment. Food Control 2016;70:74-78.

Abu Al-Soud W, Radstrom P. Effects of amplification facilitators on diagnostic PCR in the presence of blood, feces, and meat. J Clin Microbiol 2000;38:4463-4470.

Ahmad F, Seyrig G, Tourlousse DM, Stedtfeld RD, Tiedje JM, Hashsham SA. A CCD-based fluorescence imaging system for real-time loop-mediated isothermal amplification-based rapid and sensitive detection of waterborne pathogens on microchips. Biomed Microdevices 2011;13:929-937.

Ahn Y-C, Cho M-H, Yoon I-K, et al. Detection of Salmonella using the loop mediated isothermal amplification and realtime PCR. J Korean Chem Soc 2010;54:215-221.

AOAC. AOAC INTERNATIONAL Methods Committee Guidelines for Validation of Microbiological Methods for Food and Environmental Surfaces. 2012. Available at: http:// www.eoma.aoac.org/app_j.pdf Accessed March 1, 2018.

Bapanpally C, Montier L, Khan S, Kasra A, Brunelle SL. SAS molecular tests Salmonella detection kit. Performance tested method 021202. J AOAC Int 2014;97:808-819.

Bird P, Fisher K, Boyle M, et al. Evaluation of 3M Molecular Detection Assay (MDA) Salmonella for the detection of Salmonella in selected foods: Collaborative study. J AOAC Int 2013;96:1325-1335.

Bird P, Fisher K, Boyle M, et al. Evaluation of modification of the 3M Molecular Detection Assay (MDA) Salmonella method (2013.09) for the detection of Salmonella in selected foods: Collaborative study. J AOAC Int 2014;97:1329_ 1342.

Bird P, Flannery J, Crowley E, Agin JR, Goins D, Monteroso L. Evaluation of the 3M Molecular Detection Assay (MDA) 2Salmonella for the detection of Salmonella spp. in select foods and environmental surfaces: Collaborative study, first action 2016.01. J AOAC Int 2016;99:980-997.
Birmpa A, Kalogeropoulos K, Kokkinos P, Vantarakis A. Evaluation of two loop-mediated isothermal amplification methods for the detection of Salmonella Enteritidis and Listeria monocytogenes in artificially contaminated ready-to-eat fresh produce. Ital J Food Saf 2015a;4:5383.

Birmpa A, Kouroupis G, Kalogeropoulos K, Kokkinos P, Kritsonis P, Vantarakis A. A loop-mediated isothermal amplification platform for the detection of foodborne pathogens. J Bioeng Biomed Sci 2015b;5:3.

Bonardi S, Alpigiani I, Bacci C, Brindani F, Pongolini S. Comparison of an isothermal amplification and bioluminescence detection of DNA method and ISO 6579:2002 for the detection of Salmonella enterica serovars in retail meat samples. J Food Prot 2013;76:657-661.

CDC. Reports of Selected Salmonella Outbreak Investigations. 2018. Available at: http://www.cdc.gov/salmonella/outbreaks .html Accessed March 1, 2018.

Chen C, Liu P, Zhao X, Du W, Feng XJ, Liu BF. A selfcontained microfluidic in-gel loop-mediated isothermal amplification for multiplexed pathogen detection. Sens Actuators B Chem 2017;239:1-8.

Chen S, Wang F, Beaulieu JC, Stein RE, Ge B. Rapid detection of viable salmonellae in produce by coupling propidium monoazide with loop-mediated isothermal amplification. Appl Environ Microbiol 2011;77:4008-4016.

Chen Z, Zhang K, Yin H, Li Q, Wang L, Liu Z. Detection of Salmonella and several common Salmonella serotypes in food by loop-mediated isothermal amplification method. Food Sci Human Wellness 2015;4:75-79.

Cho AR, Dong HJ, Cho S. Rapid and sensitive detection of Salmonella spp. by using a loop-mediated isothermal amplification assay in duck carcass sample. Korean J Food Sci Anim Resour 2013;33:655-663.

D’Agostino M, Diez-Valcarce M, Robles S, Losilla-Garcia B, Cook N. A loop-mediated isothermal amplification-based method for analysing animal feed for the presence of Salmonella. Food Anal Method 2015;8:2409-2416.

D'Agostino M, Robles S, Hansen F, et al. Validation of a loopmediated amplification/ISO 6579-based method for analysing soya meal for the presence of Salmonella enterica. Food Anal Method 2016;9:2979-2985.

de Paz HD, Brotons P, Munoz-Almagro C. Molecular isothermal techniques for combating infectious diseases: Towards low-cost point-of-care diagnostics. Expert Rev Mol Diagn 2014;14:827-843.

Deng Y, Ji LL, Li L, Li B, Su JY. Development and application of a novel nucleic amplification kit on detection of several pathogens. Appl Mech Mater 2014;618:293-297.

Domesle KJ, Yang Q, Hammack TS, Ge B. Validation of a Salmonella loop-mediated isothermal amplification assay in animal food. Int J Food Microbiol 2018;264:63-76.

Draz MS, Lu X. Development of a loop mediated isothermal amplification (LAMP) — surface enhanced raman spectroscopy (SERS) assay for the detection of Salmonella enterica serotype Enteritidis. Theranostics 2016;6:522532.

Duarte C, Salm E, Dorvel B, Reddy B, Jr., Bashir R. On-chip parallel detection of foodborne pathogens using loop-mediated isothermal amplification. Biomed Microdevices 2013;15:821830.

DuVall JA, Borba JC, Shafagati N, et al. Optical imaging of paramagnetic bead-DNA aggregation inhibition allows for low copy number detection of infectious pathogens. PLoS One 2015;10:e129830. 
EFSA. European Commission on Microbiological Risk Assessment in feedingstuffs for food-producing animals, Scientific Opinion of the Panel on Biological Hazards on a request from the Health and Consumer Protection Directorate General. EFSA J 2008;720:1-84.

Eiken Chemical Co. Ltd. The Principle of LAMP Method. 2005. Available at: http://loopamp.eiken.co.jp/e/lamp/principle .html Accessed March 1, 2018.

Eiken Chemical Co. Ltd. A Guide to LAMP Primer Designing. 2009. Available at: https://primerexplorer.jp/e/v4_manual/ pdf/PrimerExplorerV4_Manual_1.pdf Accessed March 1, 2018.

Fang J, Wu Y, Qu D, et al. Propidium monoazide real time loopmediated isothermal amplification for specific visualization of viable Salmonella in food. Lett Appl Microbiol 2018. [Epub ahead of print].

FAO/WHO. Executive Summary Report of the Joint FAO/ WHO Expert Meeting on Hazards Associated with Animal Feed. 2015. Available at: http://www.fao.org/3/a-az851e.pdf Accessed March 1, 2018.

FDA. Compliance Policy Guide Sec. 690.800 Salmonella in Food for Animals. 2013. Available at: https://www.fda .gov/downloads/iceci/compliancemanuals/compliancepolicy guidancemanual/ucm361105.pdf Accessed March 1, 2018.

FDA. Guidelines for the Validation of Analytical Methods for the Detection of Microbial Pathogens in Foods and Feeds, 2nd ed. 2015. Available at: https://www.fda.gov/downloads/ ScienceResearch/FieldScience/UCM298730 Accessed March $1,2018$.

FDA. 21 CFR Part 117: Current Good Manufacturing Practice, Hazard Analysis, and Risk-Based Preventive Controls for Human Food. Available at: https://www.ecfr.gov/cgi-bin/ text-idx?SID=2dae3ed6aff60a1d08b2c1e418057788\&mc= true \&node $=$ t21.2.117\&rgn=div5 Accessed June 1, 2018.

FDA. 21 CFR Part 507: Current Good Manufacturing Practice, Hazard Analysis, and Risk-Based Preventive Controls for Food for Animals. Available at: https://www.ecfr.gov/cgibin/text-idx?SID=2dae3ed6aff60a1d08b2c1e418057788\&mc= true\&node $=$ t21.6.507\&rgn=div5 Accessed June 1, 2018.

Ferguson BS. A look at the microbiology testing market. Food Safety Magazine 2017:14-15. Available at: https://www .foodsafetymagazine.com/magazine-archive1/februarymarch2017/a-look-at-the-microbiology-testing-market/ Accessed March 1, 2018.

Francois $\mathrm{P}$, Tangomo M, Hibbs J, et al. Robustness of a loopmediated isothermal amplification reaction for diagnostic applications. FEMS Immunol Med Microbiol 2011;62:41-48.

Futoma-Koloch B, Ksiazczyk M, Korzekwa K, et al. Selection and electrophoretic characterization of Salmonella enterica subsp. enterica biocide variants resistant to antibiotics. Pol J Vet Sci 2015;18:725-732.

Galan JE, Ginocchio C, Costeas P. Molecular and functional characterization of the Salmonella invasion gene invA: Homology of InvA to members of a new protein family. $\mathbf{J}$ Bacteriol 1992;174:4338-4349.

Gandelman OA, Church VL, Moore CA, et al. Novel bioluminescent quantitative detection of nucleic acid amplification in real-time. PLoS One 2010;5:e14155.

Garrido-Maestu A, Azinheiro S, Carvalho J, et al. Combination of microfluidic loop-mediated isothermal amplification with gold nanoparticles for rapid detection of Salmonella spp. in food samples. Front Microbiol 2017a;8:2159.

Garrido-Maestu A, Fucinos P, Azinheiro S, Carvalho J, Prado M. Systematic loop-mediated isothermal amplification assays for rapid detection and characterization of Salmonella spp., Enteritidis and Typhimurium in food samples. Food Control 2017b;80:297-306.

Ge B, Meng J. Advanced technologies for pathogen and toxin detection in foods: Current applications and future directions. JALA 2009;14:235-241.

Gong J, Zhuang L, Zhu C, et al. Loop-mediated isothermal amplification of the sefA gene for rapid detection of Salmonella Enteritidis and Salmonella Gallinarum in chickens. Foodborne Pathog Dis 2016;13:177-181.

Hara-Kudo Y, Yoshino M, Kojima T. Ikedo M. Loop-mediated isothermal amplification for the rapid detection of Salmonella. FEMS Microbiol Lett 2005;253:155-161.

He C, Liu Z, Wang D, Sun Q, Huang J. Applicatio of LAMP to detect Salmonella in animal derived foods. Chin J Food Hyg 2010;5:411-414.

Hsieh K, Mage PL, Csordas AT, Eisenstein M, Soh HT. Simultaneous elimination of carryover contamination and detection of DNA with uracil-DNA-glycosylase-supplemented loop-mediated isothermal amplification (UDG-LAMP). Chem Commun (Camb) 2014;50:3747-3749.

Hsieh K, Patterson AS, Ferguson BS, Plaxco KW, Soh HT. Rapid, sensitive, and quantitative detection of pathogenic DNA at the point of care through microfluidic electrochemical quantitative loop-mediated isothermal amplification. Angew Chem Int Ed Engl 2012;51:4896-4900.

$\mathrm{Hu}$ L, Ma LM, Zheng S, et al. Evaluation of 3M Molecular Detection System and ANSR Pathogen Detection System for rapid detection of Salmonella from egg products. Poult Sci 2017;96:1410-1418.

Hu L, Ma LM, Zheng S, et al. Development of a novel loopmediated isothermal amplification (LAMP) assay for the detection of Salmonella ser. Enteritidis from egg products. Food Control 2018;88:190-197.

[IFSAC] Interagency Food Safety Analytics Collaboration. Foodborne illness source attribution estimates for Salmonella, Escherichia coli O157 (E. coli O157), Listeria monocytogenes (Lm), and Campylobacter using outbreak surveillance data. Washington, DC, 2015. Available at: http://www .cdc.gov/foodsafety/pdfs/ifsac-project-report-508c.pdf Accessed March 1, 2018.

[IFSAC] Interagency Food Safety Analytics Collaboration. Foodborne illness source attribution estimates for 2013 for Salmonella, Escherichia coli O157, Listeria monocytogenes, and Campylobacter using multi-year outbreak surveillance data, United States. Washington, DC, 2017. Available at: https://www.cdc.gov/foodsafety/pdfs/IFSAC-2013Foodborne illnessSourceEstimates-508.pdf Accessed March 1, 2018.

ISO. ISO 16140-2:2016 Microbiology of the Food ChainMethod Validation-Part 2: Protocol for the Validation of Alternative (Proprietary) Methods Against a Reference Method. Geneva, 2016. Available at: https://www.iso.org/ standard/54870.html Accessed March 1, 2018.

Jenkins DM, Kubota R, Dong J, Li Y, Higashiguchi D. Handheld device for real-time, quantitative, LAMP-based detection of Salmonella enterica using assimilating probes. Biosens Bioelectron 2011;30:255-260.

Jiang K, Lv QF, Zhang DL, et al. A novel, sensitive, accurate multiplex loop-mediated isothermal amplification method for detection of Salmonella spp., Shigella spp. and Staphylococcus aureus in food. J Food Agric Environ 2012;10:252256.

Kaneko H, Kawana T, Fukushima E, Suzutani T. Tolerance of loop-mediated isothermal amplification to a culture medium 
and biological substances. J Biochem Biophys Methods 2007; 70:499-501.

Kirk MD, Pires SM, Black RE, et al. World Health Organization estimates of the global and regional disease burden of 22 foodborne bacterial, protozoal, and viral diseases, 2010: A data synthesis. PLoS Med 2015;12:e1001921.

Kokkinos PA, Ziros PG, Bellou M, Vantarakis A. Loopmediated isothermal amplification (LAMP) for the detection of Salmonella in food. Food Anal Method 2014;7:512-526.

Kubota R, Jenkins DM. Real-time duplex applications of loopmediated amplification (LAMP) by assimilating probes. Int $\mathrm{J}$ Mol Sci 2015;16:4786-4799.

Kubota R, Labarre P, Weigl BH, Li Y, Haydock P, Jenkins DM. Molecular diagnostics in a teacup: Non-instrumented nucleic acid amplification (NINA) for rapid, low cost detection of Salmonella enterica. Chin Sci Bull 2013;58:1162-1168.

Kumar PP, Agarwal RK, Thomas P, et al. Rapid detection of Salmonella enterica subspecies enterica serovar Typhimurium by loop mediated isothermal amplification (LAMP) test from field chicken meat samples. Food Biotechnol 2014;28:50-62.

Kumar Y, Bansal S, Jaiswal P. Loop-mediated isothermal amplification (LAMP): A rapid and sensitive tool for quality assessment of meat products. Compr Rev Food Sci F 2017; 16:1359-1378.

Kundapur RR, Nema V. Loop-mediated isothermal amplification: Beyond microbial identification. Cogent Biol 2016;2:1137110.

Li JJ, Zhai LG, Bie XM, et al. A novel visual loop-mediated isothermal amplification assay targeting gene62181533 for the detection of Salmonella spp. in foods. Food Control 2016; 60:230-236.

Li X, Zhang S, Zhang H, et al. A loop-mediated isothermal amplification method targets the phoP gene for the detection of Salmonella in food samples. Int J Food Microbiol 2009; 133:252-258.

Li YM, Fan PH, Zhou SS, Zhang L. Loop-mediated isothermal amplification (LAMP): A novel rapid detection platform for pathogens. Microb Pathog 2017;107:54-61.

Lim HS, Zheng Q, Miks-Krajnik M, Turner M, Yuk HG. Evaluation of commercial kit based on loop-mediated isothermal amplification for rapid detection of low levels of uninjured and injured Salmonella on duck meat, bean sprouts, and fishballs in Singapore. J Food Prot 2015;78:1203-1207.

Liu N, Zou D, Dong D, et al. Development of a multiplex loopmediated isothermal amplification method for the simultaneous detection of Salmonella spp. and Vibrio parahaemolyticus. Sci Rep 2017;7:45601.

Loff M, Mare L, de Kwaadsteniet M, Khan W. 3M Molecular Detection System versus MALDI-TOF mass spectrometry and molecular techniques for the identification of Escherichia coli 0157:H7, Salmonella spp. \& Listeria spp. J Microbiol Methods 2014;101:33-43.

Lu YX, Yang WQ, Shi L, et al. Specific detection of viable Salmonella cells by an ethidium monoazide-loop mediated isothermal amplification (EMA-LAMP) method. J Health Sci 2009;55:820-824.

Mabey D, Peeling RW, Ustianowski A, Perkins MD. Diagnostics for the developing world. Nat Rev Microbiol 2004;2: 231-240.

Maciorowski KG, Pillai SD, Jones FT, Ricke SC. Polymerase chain reaction detection of foodborne Salmonella spp. in animal feeds. Crit Rev Microbiol 2005;31:45-53.

Malorny B, Paccassoni E, Fach P, Bunge C, Martin A, Helmuth R. Diagnostic real-time PCR for detection of Salmonella in food. Appl Environ Microbiol 2004;70:7046-7052.
Mashooq M, Kumar D, Niranjan AK, Agarwal RK, Rathore R. Development and evaluation of probe based real time loop mediated isothermal amplification for Salmonella: A new tool for DNA quantification. J Microbiol Methods 2016;126: 24-29.

Mayboroda O, Katakis I, O'Sullivan CK. Multiplexed isothermal nucleic acid amplification. Anal Biochem 2018;545: 20-30.

Mori Y, Kanda H, Notomi T. Loop-mediated isothermal amplification (LAMP): Recent progress in research and development. J Infect Chemother 2013;19:404-411.

Mori Y, Nagamine K, Tomita N, Notomi T. Detection of loopmediated isothermal amplification reaction by turbidity derived from magnesium pyrophosphate formation. Biochem Biophys Res Commun 2001;289:150-154.

Nagamine K, Hase T, Notomi T. Accelerated reaction by loopmediated isothermal amplification using loop primers. Mol Cell Probes 2002;16:223-229.

Niemz A, Ferguson TM, Boyle DS. Point-of-care nucleic acid testing for infectious diseases. Trends Biotechnol 2011;29: 240-250.

Niessen L, Luo J, Denschlag C, Vogel RF. The application of loop-mediated isothermal amplification (LAMP) in food testing for bacterial pathogens and fungal contaminants. Food Microbiol 2013;36:191-206.

Notomi T, Okayama H, Masubuchi H, et al. Loop-mediated isothermal amplification of DNA. Nucleic Acids Res 2000; 28:E63.

Nyan DC, Swinson KL. A novel multiplex isothermal amplification method for rapid detection and identification of viruses. Sci Rep 2015;5:17925.

Oh SJ, Park BH, Choi G, et al. Fully automated and colorimetric foodborne pathogen detection on an integrated centrifugal microfluidic device. Lab Chip 2016a;16:1917-1926.

Oh SJ, Park BH, Jung JH, et al. Centrifugal loop-mediated isothermal amplification microdevice for rapid, multiplex and colorimetric foodborne pathogen detection. Biosens Bioelectron 2016b;75:293-300.

Ohtsuka K, Yanagawa K, Takatori K, Hara-Kudo Y. Detection of Salmonella enterica in naturally contaminated liquid eggs by loop-mediated isothermal amplification, and characterization of Salmonella isolates. Appl Environ Microbiol 2005; 71:6730-6735.

Okamura M, Ohba Y, Kikuchi S, et al. Loop-mediated isothermal amplification for the rapid, sensitive, and specific detection of the O9 group of Salmonella in chickens. Vet Microbiol 2008;132:197-204.

Okamura M, Ohba Y, Kikuchi S, et al. Rapid, sensitive, and specific detection of the $\mathrm{O} 4$ group of Salmonella enterica by loop-mediated isothermal amplification. Avian Dis 2009;53: 216-221.

Papadakis G, Murasova P, Hamiot A, et al. Micro-nano-bio acoustic system for the detection of foodborne pathogens in real samples. Biosens Bioelectron 2018;111:52-58.

Park BH, Oh SJ, Jung JH, et al. An integrated rotary microfluidic system with DNA extraction, loop-mediated isothermal amplification, and lateral flow strip based detection for point-of-care pathogen diagnostics. Biosens Bioelectron 2017;91:334-340.

Patterson AS, Heithoff DM, Ferguson BS, Soh HT, Mahan MJ, Plaxco KW. Microfluidic chip-based detection and intraspecies strain discrimination of Salmonella serovars derived from whole blood of septic mice. Appl Environ Microbiol 2013;79:2302-2311. 
Rahn K, De Grandis SA, Clarke RC, et al. Amplification of an invA gene sequence of Salmonella Typhimurium by polymerase chain reaction as a specific method of detection of Salmonella. Mol Cell Probes 1992;6:271-279.

Ravan H, Yazdanparast R. Development and evaluation of a loopmediated isothermal amplification method in conjunction with an enzyme-linked immunosorbent assay for specific detection of Salmonella serogroup D. Anal Chim Acta 2012a;733:64-70.

Ravan H, Yazdanparast R. Development of a new loopmediated isothermal amplification assay for prt $(r f b S)$ gene to improve the identification of Salmonella serogroup D. World J Microbiol Biotechnol 2012b;28:2101-2106.

Safavieh M, Kanakasabapathy MK, Tarlan F, et al. Emerging loop-mediated isothermal amplification-based microchip and microdevice technologies for nucleic acid detection. Acs Biomater Sci Eng 2016;2:278-294.

Santiago-Felipe S, Tortajada-Genaro LA, Carrascosa J, Puchades R, Maquieira A. Real-time loop-mediated isothermal DNA amplification in compact disc micro-reactors. Biosens Bioelectron 2016;79:300-306.

Sarowska J, Frej-Madrzak M, Jama-Kmiecik A, Kilian A, Teryks-Wolyniec D, Choroszy-Krol I. Detection of Salmonella in foods using a reference PN-ISO method and an alternative method based on loop-mediated isothermal amplification coupled with bioluminescence. Adv Clin Exp Med 2016;25: 945-950.

Sayad A, Ibrahim F, Mukim Uddin S, Cho J, Madou M, Thong KL. A microdevice for rapid, monoplex and colorimetric detection of foodborne pathogens using a centrifugal microfluidic platform. Biosens Bioelectron 2018;100:96-104.

Sayad AA, Ibrahim F, Uddin SM, et al. A microfluidic lab-on-adisc integrated loop mediated isothermal amplification for foodborne pathogen detection. Sens Actuators B Chem 2016; 227:600-609.

Seo JH, Park BH, Oh SJ, et al. Development of a highthroughput centrifugal loop-mediated isothermal amplification microdevice for multiplex foodborne pathogenic bacteria detection. Sens Actuators B Chem 2017;246:146-153.

Shao Y, Zhu S, Jin C, Chen F. Development of multiplex loopmediated isothermal amplification-RFLP (mLAMP-RFLP) to detect Salmonella spp. and Shigella spp. in milk. Int J Food Microbiol 2011;148:75-79.

Soli KW, Kas M, Maure T, et al. Evaluation of colorimetric detection methods for Shigella, Salmonella, and Vibrio cholerae by loop-mediated isothermal amplification. Diagn Microbiol Infect Dis 2013;77:321-323.

Srisawat M, Panbangred W. Efficient and specific detection of Salmonella in food samples using a stn-based loop-mediated isothermal amplification method. Biomed Res Int 2015;2015: 356401.

Sun Y, Quyen TL, Hung TQ, Chin WH, Wolff A, Bang DD. A lab-on-a-chip system with integrated sample preparation and loop-mediated isothermal amplification for rapid and quantitative detection of Salmonella spp. in food samples. Lab Chip 2015;15:1898-1904.

Tang T, Cheng A, Wang M, et al. Development and clinical verification of a loop-mediated isothermal amplification method for detection of Salmonella species in suspect infected ducks. Poult Sci 2012;91:979-986.

Tanner NA, Zhang Y, Evans TC, Jr. Simultaneous multiple target detection in real-time loop-mediated isothermal amplification. Biotechniques 2012;53:81-89.

Techathuvanan C, D'Souza DH. Reverse-transcriptase loopmediated isothermal amplification as a rapid screening/ monitoring tool for Salmonella enterica detection in liquid whole eggs. J Food Sci 2012;77:M200-M205.

Techathuvanan C, Draughon FA, D'Souza DH. Loop-mediated isothermal amplification (LAMP) for the rapid and sensitive detection of Salmonella Typhimurium from pork. J Food Sci 2010;75:M165-M172.

Techathuvanan C, Draughon FA, D'Souza DH. Comparison of reverse transcriptase PCR, reverse transcriptase loopmediated isothermal amplification, and culture-based assays for Salmonella detection from pork processing environments. J Food Prot 2011;74:294-301.

Tourlousse DM, Ahmad F, Stedtfeld RD, Seyrig G, Tiedje JM, Hashsham SA. A polymer microfluidic chip for quantitative detection of multiple water- and foodborne pathogens using real-time fluorogenic loop-mediated isothermal amplification. Biomed Microdevices 2012;14:769-778.

Uddin SM, Ibrahim F, Sayad AA, et al. A portable automatic endpoint detection system for amplicons of loop mediated isothermal amplification on microfluidic compact disk platform. Sensors (Basel) 2015;15:5376-5389.

Ueda S, Kuwabara Y. The rapid detection of Salmonella from food samples by loop-mediated isothermal amplification (LAMP). Biocontrol Sci 2009;14:73-76.

Uzzau S, Brown DJ, Wallis T, et al. Host adapted serotypes of Salmonella enterica. Epidemiol Infect 2000;125:229-255.

Wang D, Huo G, Wang F, Li Y, Ren D. Drawback of loopmediated isothermal amplification. Afr J Food Sci 2008a;2: 83-86.

Wang D, Wang Y, Xiao F, et al. A comparison of in-house realtime lamp assays with a commercial assay for the detection of pathogenic bacteria. Molecules 2015a;20:9487-9495.

Wang F, Yang Q, Kase JA, et al. Current trends in detecting non-O157 Shiga toxin-producing Escherichia coli in food. Foodborne Pathog Dis 2013;10:665-677.

Wang L, Shi L, Alam MJ, Geng Y, Li L. Specific and rapid detection of foodborne Salmonella by loop-mediated isothermal amplification method. Food Res Int 2008b;41:69-74.

Wang T, Kim S, An J.H. A novel CMOS image sensor system for quantitative loop-mediated isothermal amplification assays to detect food-borne pathogens. J Microbiol Methods 2017;133:1-7.

Wang Y, Wang Y, Lan R, et al. Multiple endonuclease restriction real-time loop-mediated isothermal amplification: A novel analytically rapid, sensitive, multiplex loop-mediated isothermal amplification detection technique. J Mol Diagn 2015b;17:392-401.

Wang Y, Wang Y, Luo L, et al. Rapid and sensitive detection of Shigella spp. and Salmonella spp. by multiple endonuclease restriction real-time loop-mediated isothermal amplification technique. Front Microbiol 2015c;6:1400.

Wang YZ, Wang DG. Development and evaluation of a loopmediated isothermal amplification (LAMP) method for detecting foodborn Salmonella in raw milk. Adv Mat Res 2013; 647:577-582.

WHO. The Use of Loop-Mediated Isothermal Amplification (TB-LAMP) for the Diagnosis of Pulmonary Tuberculosis: Policy Guidance. 2016. Available at: http://www.who.int/tb/ publications/lamp-diagnosis-molecular/en/ Accessed March $1,2018$.

WHO. Salmonella (Non-Typhoidal) Fact Sheet. 2017. Available at: http://www.who.int/mediacentre/factsheets/fs139/en/ Accessed March 1, 2018.

Wu GP, Chen SH, Levin RE. Application of ethidium bromide monoazide for quantification of viable and dead cells of 
Salmonella enterica by real-time loop-mediated isothermal amplification. J Microbiol Methods 2015a;117:41-48.

Wu GP, Chen SH, Levin RE. Rapid real-time loop-mediated isothermal amplification combined with coated activated carbon for detection of low numbers of Salmonella enterica from lettuce without enrichment. Food Control 2015b;56: 47-52.

Wu GP, Levin RE. Rapid and sensitive detection of Salmonella enterica ser. Enteritis retrieved from lettuce using a real-time loop-mediated amplification isothermal assay without enrichment. Food Biotechnol 2015;29:263-275.

Xia Y, Liu ZH, Yan SQ, Yin F, Feng XJ, Liu BF. Identifying multiple bacterial pathogens by loop-mediated isothermal amplification on a rotate \& react slipchip. Sens Actuators B Chem 2016;228:491-499.

Xiong ZY, Zhang JP, Kang M. Sensitive and specific detection of foodborne pathogens in pork by a loop-mediated isothermal amplification methodology. Acta Medica Mediterr 2016; 32:1143-1147.

Yan M, Li W, Zhou Z, Peng H, Luo Z, Xu L. Direct detection of various pathogens by loop-mediated isothermal amplification assays on bacterial culture and bacterial colony. Microb Pathog 2017;102:1-7.

Yang JL, Ma GP, Yang R, et al. Simple and rapid detection of Salmonella serovar Enteritidis under field conditions by loopmediated isothermal amplification. J Appl Microbiol 2010; 109:1715-1723.

Yang Q, Chen S, Ge B. Detecting Salmonella serovars in shell eggs by loop-mediated isothermal amplification. J Food Prot 2013;76:1790-1796.

Yang Q, Domesle KJ, Wang F, Ge B. Rapid detection of Salmonella in food and feed by coupling loop-mediated isothermal amplification with bioluminescent assay in real-time. BMC Microbiol 2016;16:112.

Yang Q, Wang F, Jones KL, Meng J, Prinyawiwatkul W, Ge B. Evaluation of loop-mediated isothermal amplification for the rapid, reliable, and robust detection of Salmonella in produce. Food Microbiol 2015;46:485-493.

Yang Q, Wang F, Prinyawiwatkul W, Ge B. Robustness of Salmonella loop-mediated isothermal amplification assays for food applications. J Appl Microbiol 2014;116:81-88.

Ye Y, Yamasaki S, Lei S. In situ loop-mediated isothermal amplification technology for rapid detection of food-borne Salmonella. Food Ferment Ind 2009;35:137-141.

Ye YX, Wang B, Huang F, et al. Application of in situ loopmediated isothermal amplification method for detection of Salmonella in foods. Food Control 2011;22:438-444.

Youn SY, Jeong OM, Choi BK, Jung SC, Kang MS. Application of loop-mediated isothermal amplification with propidium monoazide treatment to detect live Salmonella in chicken carcasses. Poult Sci 2017;96:458-464.
Zhang G, Brown EW, Gonzalez-Escalona N. Comparison of realtime PCR, reverse transcriptase real-time PCR, loop-mediated isothermal amplification, and the FDA conventional microbiological method for the detection of Salmonella spp. in produce. Appl Environ Microbiol 2011;77:6495-6501.

Zhang L, Pan ZM, Geng SZ, et al. A loop-mediated isothermal amplification method targets the hisJ gene for the detection of foodborne Salmonella. Eur Food Res Technol 2012a;234: 1055-1062.

Zhang L, Tian F, Liu C, et al. Hand-powered centrifugal microfluidic platform inspired by the spinning top for sample-to-answer diagnostics of nucleic acids. Lab Chip 2018;18:610-619.

Zhang X, Lowe SB, Gooding JJ. Brief review of monitoring methods for loop-mediated isothermal amplification (LAMP). Biosens Bioelectron 2014;61:491-499.

Zhang YQ, Shan XX, Shi L, et al. Development of a fimY-based loop-mediated isothermal amplification assay for detection of Salmonella in food. Food Res Int 2012b;45:1011-1015.

Zhao XH, Wang L, Chu J, et al. Development and application of a rapid and simple loop-mediated isothermal amplification method for food-borne Salmonella detection. Food Sci Biotechnol 2010;19:1655-1659.

Zhao Y, Jiang X, Qu Y, et al. Salmonella detection in powdered dairy products using a novel molecular tool. J Dairy Sci 2017; 100:3480-3496.

Zhu LJ, Xu YC, Cheng N, et al. A facile cascade signal amplification strategy using DNAzyme loop-mediated isothermal amplification for the ultrasensitive colorimetric detection of Salmonella. Sens Actuators B Chem 2017;242:880-888.

Zhu SM, Wu JJ, Xu C, Qu J, Cheng W, Chen FS. Rapid detection of Salmonella spp. by loop-mediated isothermal amplification method. Mod Food Sci Technol 2008;24:725-730.

Zhuang L, Gong J, Li Q, et al. Detection of Salmonella spp. by a loop-mediated isothermal amplification (LAMP) method targeting bcfD gene. Lett Appl Microbiol 2014;59:658-664.

Ziros PG, Kokkinos PA, Papanotas K, Vantarakis A. Loopmediated isothermal amplification (LAMP) for the detection of Salmonella spp. isolated from different food types. J Microbiol Biotechnol Food Sci 2012;2:152-161.

Address correspondence to: Beilei Ge, PhD Division of Animal and Food Microbiology Office of Research Center for Veterinary Medicine U.S. Food and Drug Administration 8401 Muirkirk Road Laurel, MD 20708

E-mail: beilei.ge@fda.hhs.gov 